\title{
Recent development of metal compound applications in lithium-sulphur batteries
}

\author{
Xingxing $\mathrm{Gu}^{\mathrm{a})}$ \\ College of Environment and Resources, Chongqing Technology and Business University, Chongqing 400067, \\ China; and Center for Clean Environment and Energy, Environmental Futures Research Institute, Griffith School \\ of Environment, Griffith University, Gold Coast Campus, Gold Coast QLD 4222, Australia \\ Chao Lai ${ }^{\text {b) }}$ \\ School of Chemistry and Chemical Engineering, Jiangsu Key Laboratory of Green Synthetic Chemistry for \\ Functional Materials, Jiangsu Normal University, Xuzhou 221116, China
}

(Received 26 May 2017; accepted 27 June 2017)

\begin{abstract}
Lithium-sulphur ( $\mathrm{Li}-\mathrm{S})$ batteries are one of the most promising candidates for the next generation of energy storage systems to alleviate the energy crisis. However, Li-S batteries' commercialization faces the challenges of low active materials utilization, poor cycling life, and low energy density. Recently, tremendous progress has been achieved in improving the electrode performances and tap density by using the nanostructured metal compounds in $\mathrm{Li}-\mathrm{S}$ batteries. In this review, we not only present the latest various nanostructured metal compounds applications in $\mathrm{Li}-\mathrm{S}$ batteries, including metal oxides, metal sulphides, metal carbides, metal nitrides, and metal organic frameworks, but also we focus on the interaction mechanisms between these polar metal compounds with polysulphides. The issues and bottlenecks of these metal compounds are concluded and the corresponding available solutions to address these issues are proposed. This systematic discussion and proposed strategies can offer avenues to the practical application of $\mathrm{Li}-\mathrm{S}$ batteries in the near future.
\end{abstract}

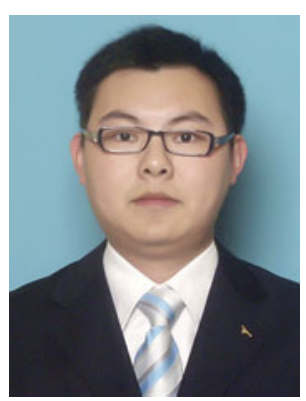

Xingxing $\mathrm{Gu}$

\begin{abstract}
Xingxing Gu received his B.S. degree in Pharmaceutical Engineering from Chongqing University of Posts and Telecommunications in 2010 and Master's degree in Analytical Chemistry from Zhejiang Normal University in 2013. Afterwards he went to Griffith University to pursue his doctoral degree under the supervision of Prof. Shanqing Zhang (Griffith University) and Prof. Yanglong Hou (Peking University). In April, 2017, he was successfully awarded the Doctor of Philosophy in Chemistry at Griffith University. Lately he joined Chongqing Technology and Business University. His research interests mainly focus on synthesis and application explorations of carbon-based materials for lithium-sulfur batteries, lithium-ion batteries and sodium ion batteries. He has published several high impact factors papers in Journal of Materials Chemistry A, Nano Research, ACS Applied Materials \& Interfaces, Advanced Energy Materials, Nano Energy, etc., as the first author and co-author.
\end{abstract}

\section{INTRODUCTION}

Li-S batteries are regarded as one of the most promising rechargeable batteries that could meet the demands of the electric vehicles and grid energy storage due to its high theoretical specific energy and volumetric energy density of approximately $2600 \mathrm{~W} \mathrm{~h} / \mathrm{kg}$ and $2800 \mathrm{~W} \mathrm{~h} / \mathrm{L},{ }^{1-4}$ respectively. Additionally, sulfur as the electroactive material is not only nontoxic, cost-effective, and highly abundant on Earth, but also it possesses a safer

Contributing Editor: Sung-Yoon Chung

Address all correspondence to these authors.

a)e-mail: xingxing.gu@ griffithuni.edu.au

b) e-mail: laichao@jsnu.edu.cn

DOI: $10.1557 / \mathrm{jmr} .2017 .282$ operating voltage range $\left(1.5-2.5 \mathrm{~V}\right.$ versus $\left.\mathrm{Li} / \mathrm{Li}^{+}\right){ }^{5,6}$ All the advantages make Li-S cells extraordinarily attractive toward researchers all over the world.

However, the early research on $\mathrm{Li}-\mathrm{S}$ batteries progress slowly because it suffers several severe issues. First of all, the low electric and $\mathrm{Li}^{+}$-ionic conductivity of elemental sulfur and discharged end-product $\left(\mathrm{Li}_{2} \mathrm{~S}\right.$ and $\mathrm{Li}_{2} \mathrm{~S}_{2}$ ), which will result in low utilization of active materials and poor coulombic efficiency. ${ }^{7,8}$ Secondly and most importantly, the discharged intermediatespolysulphides easily dissolve in the organic electrolyte. ${ }^{8}$ These polysulfide anions $\left(\mathrm{S}_{x}^{2-}\right)$ can diffuse to the anode, causing tremendous loss of active materials, extremely low coulombic efficiency, and rapid capacity fading. ${ }^{6}$
(C) Materials Research Society 2017. This is an Open Access article, distributed under the terms of the Creative Commons Attribution licence (http://creativecommons.org/licenses/by/4.0/), which permits unrestricted re-use, distribution, and reproduction in any medium, provided the original work is properly cited. 
Thirdly, the huge volume expansion/shrinkage of the sulfur electrode during charge/discharge process, leads to the electrode collapse and short cycle life. ${ }^{3,6}$

Therefore multiple and combined strategies, such as developing new electrolyte and binder, ${ }^{9,10}$ protecting the anode ${ }^{11}$ modifying the separator ${ }^{12}$ and the sulfur cathode $^{13,14}$ are used to solve the above problems. Among which, using the nanostructured materials to modify the sulfur cathode are most popular. Important progress was made by Nazar and coworkers, ${ }^{15}$ who showed that by fabricating cathodes where sulfur had been encapsulated into nanostructured mesoporous carbon, high reversible capacities and good rates can be obtained due to the enhanced conductivity and physical confinement of the polysulphides via the mesopores. Since then, various nanostructured conductive carbon, such as carbon fibers, ${ }^{16}$ graphene, ${ }^{17}$ carbon nanotubes (CNT) ${ }^{13}$ carbon spheres, ${ }^{18}$ porous carbon, ${ }^{8}$ etc., have been used to improve the sulfur utilization and extend the sulfur cathode cycling performances. However, the conjugate nonpolar carbon planes have limited sites to strongly anchor polar molecules (e.g., lithium polysulphides and (di)sulphides). ${ }^{19}$ To add anchoring sites and enhance anchoring ability of the carbon, tunable polar sites to chemically confine the polysulphides was introduced. Nanostructured carbon doped with heteroatoms $\left(\mathrm{N},{ }^{20} \mathrm{~S},{ }^{21} \mathrm{P}^{22} \mathrm{~B}^{23}\right)$, and carbon modified with functional groups (amino-functionized, ${ }^{24}$ carboxylfunctioned, ${ }^{25}$ sulfonated, ${ }^{26}$ fluorinated, ${ }^{27}$ hydroxylated ${ }^{28}$ ) as well as combined with conductive polymers, ${ }^{29-31}$ have all been widely investigated for obtaining highperformance Li-S batteries. However the tap densities of these conductive carbon are commonly very low, ${ }^{32}$ which is not beneficial to the practical applications of $\mathrm{S}$ cathodes.

Recently, to increase the tap density of electrodes as well as to keep long cycle life-span, nanostructured polar metal compounds, such as metal oxides, ${ }^{33,34}$ metal hydroxides, ${ }^{13}$ metal sulphides, ${ }^{35,36}$ metal carbides, ${ }^{37}$ metal nitrides, ${ }^{38}$ and metal organic frameworks (MOFs), ${ }^{39}$ have been used as the host materials toward (poly)sulphides. A large amount of work nowadays reports that these metal compounds have much stronger adsorption ability to polysulphides compared to carbon, doped carbon, and conductive polymers. ${ }^{35,40-43}$ What's more, compared to the carbon materials, the metal compounds' exposed surfaces and morphologies are easier to control by chemical and physical methods. ${ }^{19}$ Thus a variety of nanostructured metal compounds were designed, such as hollow, ${ }^{34}$ porous, ${ }^{40}$ layered, ${ }^{35}$ laminar-structured, ${ }^{42}$ and so on, to effectively hold the polysulphides in $\mathrm{Li}-\mathrm{S}$ batteries. However, compared to many reviews on the carbon and polymers materials used in $\mathrm{Li}-\mathrm{S}$ batteries, the review on metal compounds for $\mathrm{Li}-\mathrm{S}$ batteries are rare.

Herein, recent advances in the use of these metal compounds in $\mathrm{Li}-\mathrm{S}$ batteries are reviewed. We systematically conclude metal oxides, metal hydroxides, metal sulphides, metal carbides, metal nitrides, and MOFs as sulfur host, additives, interlayers, anode/cathode/ separator coatings in $\mathrm{Li}-\mathrm{S}$ batteries (Scheme 1). Also we focus on how these metal compounds interact with polysulphides from both physical and chemical aspects. Meanwhile the disadvantages and bottle-neck of these metal compounds for $\mathrm{Li}-\mathrm{S}$ batteries have also been proposed. Lastly we prospect feasible solving strategies and future development.

\section{NANOSTRUCTURED METAL OXIDES APPLICATION IN LI-S BATTERIES}

\section{A. $\mathrm{Ti}_{x} \mathrm{O}_{y}$}

$\mathrm{TiO}_{2}$, due to its natural abundance, cost-effectiveness, and polar surface, has become the most widespread and popular metal oxide applied in $\mathrm{Li}-\mathrm{S}$ batteries. ${ }^{19}$ It was first used as an additive in the mesoporous carbonsulphur cathode of $\mathrm{Li}-\mathrm{S}$ batteries by Nazar's group in $2012{ }^{44}$ They investigate the role of surface adsorption versus pore absorption by using three kinds of $\mathrm{TiO}_{2}$ with similar surface areas but different pore sizes (mesoporous $\alpha-\mathrm{TiO}_{2}$ with pore size of $5.2 \mathrm{~nm}$, mesoporous $\beta-\mathrm{TiO}_{2}$ with pore size of $9 \mathrm{~nm}$, and nonporous $\gamma-\mathrm{TiO}_{2}$, respectively) as the additives. The electrochemical results reveal that the soluble lithium polysulphides are preferentially absorbed within the pores of the nanoporous titania while the surface adsorption also plays a more minor role. Recently, Belharouak and his co-workers also investigated the effects of nano-sized $\mathrm{TiO}_{2}$ particles as the additive on the electrochemical properties. ${ }^{45}$ The

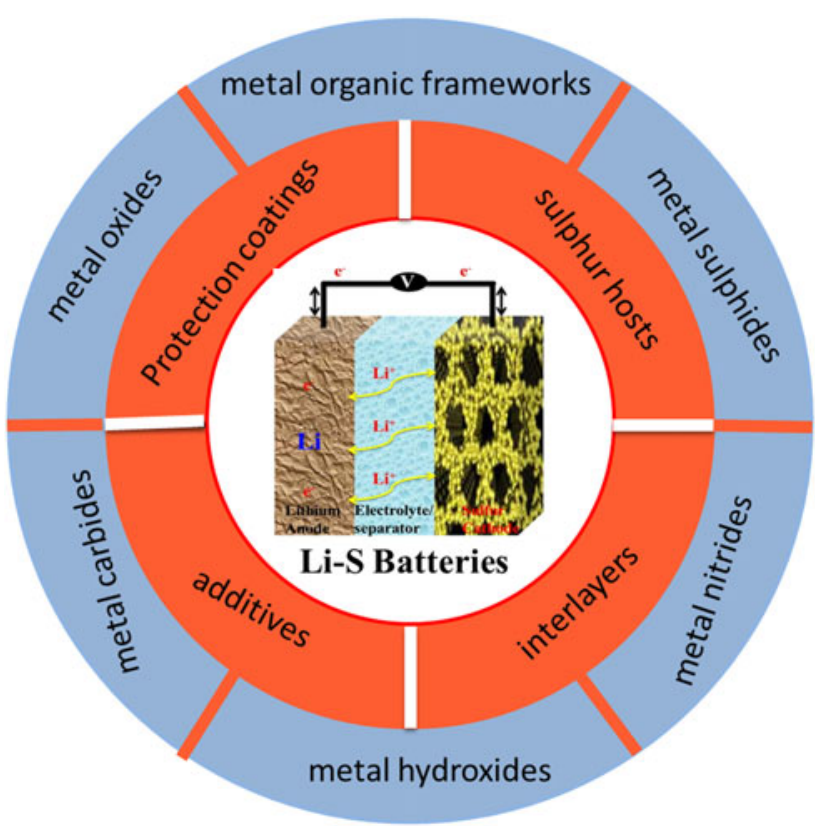

SCHEME 1. Various metal compounds acted as multiply roles in Li-S batteries. 
cyclic voltammetry measurements at different scan rate indicate that the addition of $\mathrm{TiO}_{2}$ helped in reducing the polarization of the sulfur electrodes. Wang and his coworkers designed a hydrogen reduction $\mathrm{TiO}_{2}$ hollow sphere $\left(\mathrm{H}-\mathrm{TiO}_{2}\right),{ }^{46}$ where the $\mathrm{TiO}_{2}$ micron spheres are composed of $\mathrm{TiO}_{2}$ nano-plates. With such $\mathrm{H}-\mathrm{TiO}_{2}$ additive, the sulfur cathode could deliver a high reversible capacity of $928.1 \mathrm{~mA} \mathrm{~h} / \mathrm{g}$ after 50 chargedischarge cycles at a current density of $200 \mathrm{~mA} / \mathrm{g}$. They attributed the improvement to $\mathrm{H}-\mathrm{TiO}_{2}$ spheres' polar surfaces serving as the surface-bound intermediates for strong polysulphides binding.

Nanostructured $\mathrm{TiO}_{2}$ with different morphologies as the sulfur host are also widely studied. ${ }^{34,47-54}$ Cui's group designed a sulphur- $\mathrm{TiO}_{2}$ yolk-shell nanostructure [as shown in Figs. 1(a)-1(c)], ${ }^{34}$ where the internal void space accommodates the volume expansion of sulfur and the $\mathrm{TiO}_{2}$ shell minimizes polysulfide dissolution. Accordingly, an initial specific capacity of $1030 \mathrm{~mA} \mathrm{~h} / \mathrm{g}$ at $0.5 \mathrm{C}(1 \mathrm{C}=1675 \mathrm{~mA} / \mathrm{g})$ and Coulombic efficiency of $98.4 \%$ over 1000 cycles were achieved. They also synthesized an inverse opal structure $\mathrm{TiO}_{2}$ to achieve both sulfur physical encapsulation and polysulphides binding. ${ }^{47}$ The inverse opal structure $\mathrm{TiO}_{2}$ after hydrogen reduction illustrated high conductivity. Furthermore, the relatively enclosed three dimensional (3D) structure [as shown in Figs. 1(d)-1(f)] provided an ideal architecture for sulfur and polysulphides confinement, which contributes to the $3 \mathrm{D} \mathrm{TiO}_{2}$-sulphur cathode high initial capacity of $1100 \mathrm{~mA} \mathrm{~h} / \mathrm{g}$ and reversible capacity of $890 \mathrm{~mA} \mathrm{~h} / \mathrm{g}$ after 200 cycles at $0.5 \mathrm{C}$. Such good capacity retention for the reduced $\mathrm{TiO}_{2}-\mathrm{S}$ sample is due to (i) a significantly increased electrical conductivity achieved after hydrogen reduction; (ii) rapid electron and lithium-ion transport resulted from the 3D framework and the thin $\mathrm{TiO}_{2}$ shell; (iii) the generated oxygen vacancies promoting the interaction between the $\mathrm{TiO}_{2}$ and the sulfur, which renders the rational integration of physical confinement and chemical absorption of polysulphides in a working cell. In addition, nanotube $\mathrm{TiO}_{2} / \mathrm{S}$ composite, ${ }^{50}$ nano fibers $\mathrm{TiO}_{2}-\mathrm{S}$ composites ${ }^{51}$ and mesoporous hollow $\mathrm{TiO}_{2}$ sphere-S composites, ${ }^{54}$ porous $\mathrm{TiO}_{2}-\mathrm{S}$ composites, ${ }^{48,55}$ have also been designed and fabricated a novel cathode for $\mathrm{Li}-\mathrm{S}$ batteries.

Due to the insulating nature of both $\mathrm{TiO}_{2}$ and sulfur, combining conductive carbon with $\mathrm{TiO}_{2}-\mathrm{S}$ composites to further improve the electrochemical performances is becoming increasingly favorable by the researchers. ${ }^{54-68}$ Zhang's group developed a titanium dioxide anchored on hollow carbon nanofiber hybrid nanostructure $\left(\mathrm{HCNF} @ \mathrm{TiO}_{2}-\mathrm{S}\right){ }^{66}$ The $\mathrm{HCNF} @ \mathrm{TiO}_{2}-\mathrm{S}$ composite exhibited much better electrochemical performance than the HCNF-S composite, which delivered an initial discharge capacity of $1040 \mathrm{~mA} \mathrm{~h} / \mathrm{g}$ and maintained $650 \mathrm{~mA} \mathrm{~h} / \mathrm{g}$ after 200 cycles at a $0.5 \mathrm{C}$ rate. Tilahun and his co-workers designed hybrid nanostructured microporous carbon-mesoporous carbon doped titanium dioxide/sulfur composite (MC-meso C-doped $\mathrm{TiO}_{2} / \mathrm{S}$ ). ${ }^{57}$ The incorporation of microporous carbon can effectively increase the electrical conductivity of the material by decreasing the resistance of sulfur which results in enhanced active material utilization. Simultaneously, mesoporous C-doped $\mathrm{TiO}_{2}$ nanotubes prevents the dissolution of polysulfide, and also improves the strength of
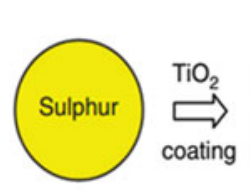

(a)

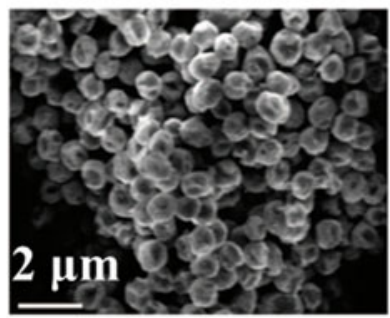

(b)
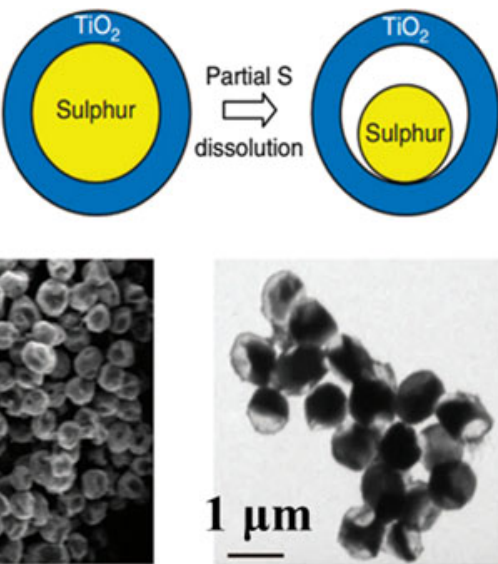

(d)

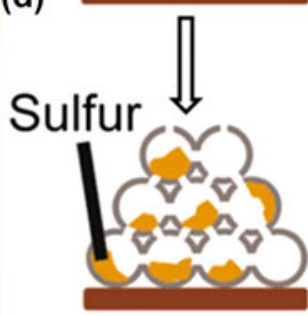

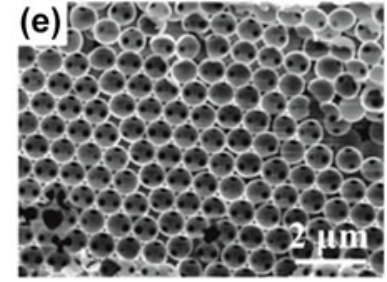

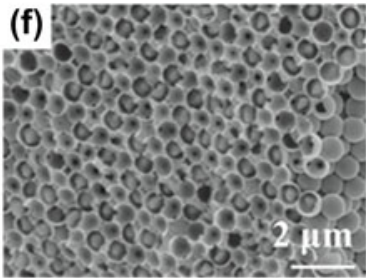

(c)

FIG. 1. (a) Synthesis and characterization of sulphur- $\mathrm{TiO}_{2}$ yolk-shell nanostructures. (b) SEM image and (c) TEM image of as-synthesized sulphur- $\mathrm{TiO}_{2}$ yolk-shell nanostructures. Reproduced with permission from Ref. 34, Copyright 2013, Nature Publishing Group. (d) Schematic of the synthetic process that involves encapsulating sulfur nanoparticles with reduced $\mathrm{TiO}_{2}$ to form $3 \mathrm{D}$ sulphur-TiO ${ }_{2-x}$ core-shell Nanostructures, (e) cross-sectional SEM image of the 3D ordered reduced $\mathrm{TiO}_{2}$ structure, (f) cross-sectional SEM image of the composite structure showing sulfur particles well encapsulated by the reduced $\mathrm{TiO}_{2}$ nanospheres. Reproduced with permission from Ref. 47, Copyright 2014, American Chemical Society. 
the entire electrode, thereby enhancing the electrochemical performance. $\mathrm{Yu}$ et al., designed a $\mathrm{TiO}_{2}$-nitrogen doped graphene/sulfur $\left(\mathrm{TiO}_{2}-\mathrm{NG} / \mathrm{S}\right)$ hybrid structures by atomic layer deposition (ALD) method. ${ }^{58}$ The nitrogen doped graphene was used as a conductive matrix and the $\mathrm{TiO}_{2}$ coating on the NG/S electrodes surface was used to inhibit lithium polysulphides shuttle. The performances of the electrodes with different cycled- $\mathrm{TiO}_{2}$ coating have been investigated. Particularly, the NG/S electrode with $20 \mathrm{TiO}_{2}$ cycles coating illustrated a high initial specific capacity of $1070 \mathrm{~mA} \mathrm{~h} / \mathrm{g}$ and a reversible capacity of $918 \mathrm{~mA} \mathrm{~h} / \mathrm{g}$ even after 500 cycles at $1 \mathrm{C}$, showing excellent potential as a cathode material for $\mathrm{Li}-\mathrm{S}$ batteries.

In addition to using $\mathrm{TiO}_{2}$ as the additive and host for the sulfur cathode, it is also used as an interlayer and a separator coating to enhance electrochemical performances. ${ }^{69-73} \mathrm{~A} \mathrm{TiO}_{2}$ nanowire-embedded graphene $\left(\mathrm{TiO}_{2}\right.$ NW/G) hybrid membrane was prepared by Manthiram's group. ${ }^{74}$ In this hybrid membrane, the graphene with high conductivity was used as the current collector, while the $\mathrm{TiO}_{2}$ NWs were used as a polysulphides shuttling inhibitor as well as the catalyst to accelerate the polysulfide reduction and oxidation. As a result, the $\mathrm{Li}_{2} \mathrm{~S}_{6}$ catholyte with such a hybrid membrane interlayer showed a high specific capacity of $1327 \mathrm{~mA} \mathrm{~h} / \mathrm{g}$ at $0.2 \mathrm{C}$ rate, a Coulombic efficiency approaching $100 \%$ and a reversible capacity of $1053 \mathrm{~mA} \mathrm{~h} / \mathrm{g}$ over 200 cycles. Recently, Fanqun $\mathrm{Li}$ and his co-workers developed a carbonized bacterial cellulose/titania $\left(\mathrm{CBC} / \mathrm{TiO}_{2}\right)$ modified separator. ${ }^{75}$ This $\mathrm{TiO}_{2}$ modified separator could restrain the shuttle effect of $\mathrm{Li}-\mathrm{S}$ cells with strong physical and chemical adsorption of polysulphides.

What's more, $\mathrm{Ti}_{4} \mathrm{O}_{7}$, another titanium oxide, has also been investigated due to its positive function in $\mathrm{Li}-\mathrm{S}$ batteries. ${ }^{76-78}$ Nazar's group firstly reported that $\mathrm{Ti}_{4} \mathrm{O}_{7}$ has a high affinity for lithium polysulphides due to the contained polar $\mathrm{O}-\mathrm{Ti}-\mathrm{O}$ units. $^{78}$ The presence of strong metal oxide-polysulfide interactions has been proved by X-ray photoelectron spectroscopy (XPS), X-ray absorption near-edge structure (XANES) and lithium polysulphides adsorption studies. Following on Cui's group reported that, compared with the $\mathrm{TiO}_{2}-\mathrm{S}$, the $\mathrm{Ti}_{4} \mathrm{O}_{7}-\mathrm{S}$ cathodes exhibited a higher reversible capacity and improved cycling performance. ${ }^{77}$ The superiorities of $\mathrm{Ti}_{4} \mathrm{O}_{7}-\mathrm{S}$ cathodes could be attributed to the strong adsorption of sulfur species on the low-coordinated $\mathrm{Ti}$ sites of $\mathrm{Ti}_{4} \mathrm{O}_{7}$, which was revealed by density functional theory (DFT).

As one of the most cost-effective, safe and controllable nanomaterials, $\mathrm{TiO}_{2}$ is a primary candidate for researchers' investigation. Polysulphides are likely to be chemically bonded at oxygen defect sites and surface defect of $\mathrm{TiO}_{2} \cdot{ }^{19}$ However, due to the insulation of $\mathrm{TiO}_{2}$, a conductive agent, such as CNT, graphene, etc., should be introduced rationally to generate a synergistic effect to produce high energy density and long life span $\mathrm{Li}-\mathrm{S}$ batteries. Meanwhile $\mathrm{Ti}_{4} \mathrm{O}_{7}$, due to its low-coordinated $\mathrm{Ti}$, is a promising polar host for the complex multielectron $\mathrm{Li}-\mathrm{S}$ conversion reaction.

\section{B. $\mathrm{Mn}_{\mathrm{x}} \mathrm{O}_{\mathrm{y}}$}

$\mathrm{MnO}_{2}$ is usually characteristically nonstoichiometric and is deficient in oxygen atoms. ${ }^{19}$ As stated above, $\mathrm{TiO}_{2}$ with oxygen defect sites and surface defects is beneficial to trap polysulphides, thus $\mathrm{MnO}_{2}$ is also a good candidate to fabricate a high performance $\mathrm{S}$ cathode..$^{14,43,52,79-81}$ In 2014, Nazar's group reported $\delta-\mathrm{MnO}_{2}$ nanosheets, which served as the prototype, react with initially formed lithium polysulphides to form surface-bound intermediates. ${ }^{81}$ Different from $\mathrm{TiO}_{2}$ chemical retention for the polysulphides, $\mathrm{MnO}_{2}$ chemical retention relied on mediating polysulfide redox through insoluble thiosulfate species in a two-step process, where the thiosulfate groups are first created in situ by oxidation of initially formed soluble lithium polysulfide species on the surface of ultrathin $\mathrm{MnO}_{2}$ nanosheets, and then the surface thiosulfate groups are proposed to anchor newly formed soluble 'higher' polysulphides by catenating them to form polythionates and converting them to insoluble 'lower' polysulphides. Because of such chemical retention mechanism, the sulfur/manganese dioxide nanosheet composite with $75 \mathrm{wt} \%$ sulfur exhibited a reversible capacity of $1300 \mathrm{~mA} \mathrm{~h} / \mathrm{g}$ at $0.2 \mathrm{C}$ and a fade rate over 2000 cycles of $0.036 \% /$ cycle at $2 \mathrm{C}$. From then on, nanowire $\alpha-\mathrm{MnO}_{2}-$ coated sulfur cathode, ${ }^{14}$ core-shell sulphur- $\delta-\mathrm{MnO}_{2}$ cathode, ${ }^{80}$ and core-shell $\gamma-\mathrm{MnO}_{2}$-coated sulfur cathode, ${ }^{79}$ have been reported in succession.

Similar to $\mathrm{TiO}_{2}$, the conductivity of $\mathrm{MnO}_{2}$ is also not good. Therefore a considerable amount of conductive additives, such as the conductive polymer or conductive carbon, should be introduced to overcome the dead active material and achieve high performances. ${ }^{43,82-85} \mathrm{Yu}$ and her co-workers designed a S/Polypyrrole- $\mathrm{MnO}_{2}(\mathrm{~S} / \mathrm{PPy}-$ $\mathrm{MnO}_{2}$ ) ternary nanostructure as shown in Fig. 2(a). ${ }^{43}$ Combining the advantages of conductive polypyrrole and $\mathrm{MnO}_{2}$, the S/Polypyrrole- $\mathrm{MnO}_{2}$ cathode with $70 \mathrm{wt} \% \mathrm{~S}$ content showed a reversible capacity of $550 \mathrm{~mA} \mathrm{~h} / \mathrm{g}$ after 500 cycles with an extremely low decay rate of $0.07 \%$ per cycle at $1 \mathrm{C}$-rate as shown in Fig. 2(b). Lou's group designed a hollow carbon nanofiber- $\mathrm{MnO}_{2}$ nanosheet-S $\left(\mathrm{MnO}_{2} @ \mathrm{HCF} / \mathrm{S}\right)$ nanostructure that the sulfur particle and $\mathrm{MnO}_{2}$ nanosheets were filled in the hollow carbon nanofiber as shown in Fig. 2(c). With such a unique structure, the $\mathrm{MnO}_{2} @ \mathrm{HCF}$ hybrid host not only facilitated electron and ion transfer during the redox reactions, but also efficiently prevented polysulfide dissolution. As a result, the $\mathrm{MnO}_{2} @ \mathrm{HCF} / \mathrm{S}$ electrode, with $71 \mathrm{wt} \% \mathrm{~S}$ content in the composite and an area of sulfur mass loading of $3.5 \mathrm{mg} / \mathrm{cm}^{2}$, maintained a reversible capacity 


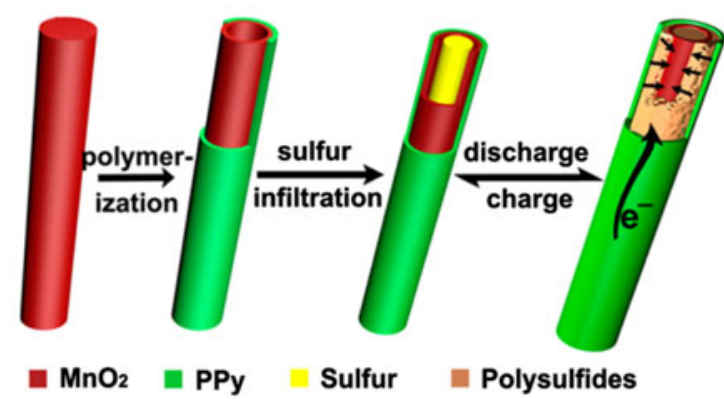

(a)

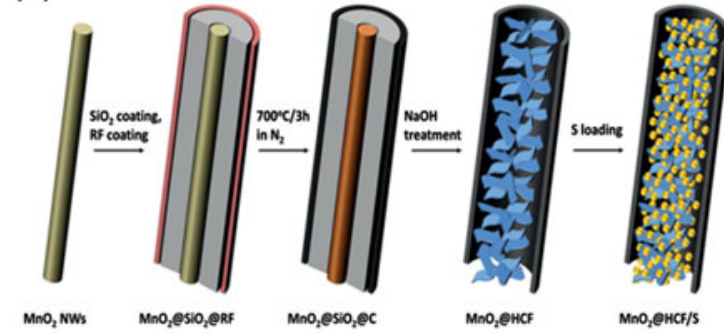

(c)

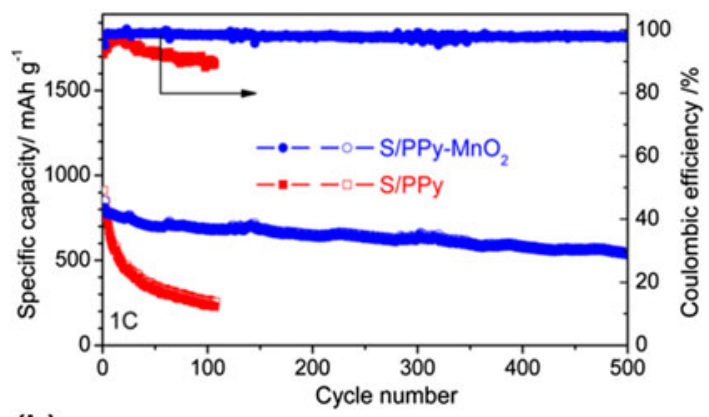

(b)

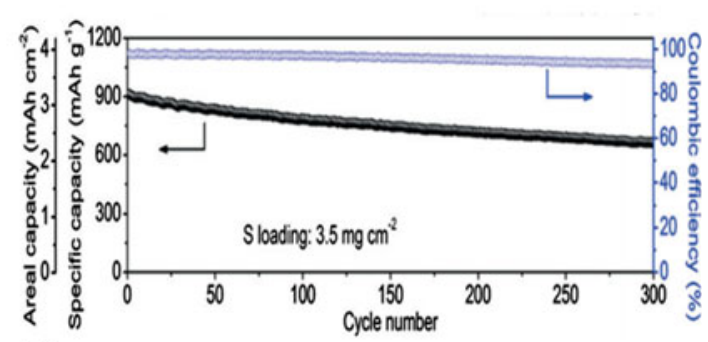

(d)

FIG. 2. (a) Illustration of the synthesis of $\mathrm{S} / \mathrm{PPy}-\mathrm{MnO}_{2}$ ternary composites. (b) Cycling performance of $\mathrm{PPy}-\mathrm{MnO}_{2}$ nanotubes encapsulated sulfur electrode compared with pure PPy nanotubes encapsulated sulfur electrode at 1 C. Reproduced with permission from Ref. 43, Copyright 2016, American Chemical Society. (c) Synthesis of the $\mathrm{MnO}_{2} @ \mathrm{HCF} / \mathrm{S}$ composite. (d) Prolonged cycling performance of $\mathrm{MnO}_{2} @ \mathrm{HCF} / \mathrm{S}$ at $0.5 \mathrm{C}$ and the corresponding Coulombic efficiency. Reproduced with permission from Ref. 84, Copyright 2015, Wiley-VCH.

of $662 \mathrm{~mA} \mathrm{~h} / \mathrm{g}$ at $0.5 \mathrm{C}$ over 300 cycles as shown in Fig. 2(d).

Recently, $\mathrm{MnO}_{2}$ and graphene composites used as the interlayer for $\mathrm{Li}-\mathrm{S}$ batteries have been reported. ${ }^{86,87}$ For example, Zhang et al., synthesized a free-standing $\mathrm{MnO}_{2}$ nanowires and graphene nanoscroll (GNSM) interlayer, where the weight ratio of graphene nanoscroll to $\mathrm{MnO}_{2}$ nanowires is $4: 1$. The insertion of the hybrid GNSM interlayer between sulfur cathode and separator could not only reduce the overall electrode resistance but also offer strong physical/chemical interactions for efficiently mitigating the shuttling of polysulphides, ensuring continuous reactivation and reutilization of the trapped sulfur active materials.

In addition, manganese monoxide ( $\mathrm{MnO})$ modified CNTs as sulfur host for improving the performance of $\mathrm{Li}-\mathrm{S}$ batteries has been reported latterly. ${ }^{88}$ The CNTs/ MnO-S cathode showed a better cycling stability over 100 cycles than CNTs-S cathodes with a same carbon/ sulfur weight ratio at around 1:8, which demonstrated $\mathrm{MnO}$ is a potential additive for sulfur cathode to address the insufficiencies of carbon hosts.

Similar to $\mathrm{TiO}_{2}, \mathrm{MnO}_{2}$ also shows strong chemical adsorption for the polysulphides. However, the mechanism of the $\mathrm{MnO}_{2}$ in the sulfur cathodes was not clearly elucidated, especially for the different polymorphs of $\mathrm{MnO}_{2}$, e.g., $\alpha-\mathrm{MnO}_{2}, \delta-\mathrm{MnO}_{2}, \gamma-\mathrm{MnO}_{2}$. In other words, the interactions between the polysulphides and $\mathrm{MnO}_{2}$ with different crystal phases should be further explored by theoretical and experimental investigations. Meanwhile other manganese based oxide, such as $\mathrm{MnO}$, $\mathrm{Mn}_{2} \mathrm{O}_{3}$ could be a promising sulfur host candidate. However, the working mechanisms also need to be further understood.

\section{C. $\mathbf{V}_{\boldsymbol{x}} \mathrm{O}_{\boldsymbol{y}}$}

$\mathrm{V}_{2} \mathrm{O}_{5}$, has been attracting much attention, as it offers the essential advantages of low cost, abundant sources, and better safety relative to commercial cathodes such as $\mathrm{LiCoO}_{2}$ and $\mathrm{LiNiO}_{2}{ }^{89}$ However, recently it has received increasing attention due to its strong interaction with polysulphides. ${ }^{90,91}$ As early as 2009 and 2010 , there were two works that reported $\mathrm{V}_{2} \mathrm{O}_{5}-\mathrm{S}$ composites as cathode materials for $\mathrm{Li}-\mathrm{S}$ batteries. ${ }^{92,93}$ $\mathrm{V}_{2} \mathrm{O}_{5}-\mathrm{S}$ composites illustrated better electrochemical performances compared to the pure sulfur cathode, wherein the researchers attributed such improvements to the addition of $\mathrm{V}_{2} \mathrm{O}_{5}$ which could decrease the resistance of the composite electrode. ${ }^{93}$ Following on, Oh et al., ${ }^{94}$ found the $\mathrm{V}_{2} \mathrm{O}_{5} /$ carbon nano-composite as an additive to the $\mathrm{Li}_{2} \mathrm{~S}_{6}$ polysulfide solution was highly effective at capturing these long-chain polysulphides on its surface. As a result, Liu and his co-workers directly used micrometer-scale $\mathrm{V}_{2} \mathrm{O}_{5}$ layer as the interlayer for $\mathrm{Li}-\mathrm{S}$ batteries. ${ }^{91}$ A $5 \mathrm{~mA}$ h pouch cell with $\mathrm{V}_{2} \mathrm{O}_{5}$ interlayer could cycle 300 times over 1 year without noticeable degradation. Additionally a $\mathrm{V}_{2} \mathrm{O}_{5^{-}}$ decorated carbon nanofiber interlayer for suppressing 
self-discharge and shuttle effect has also been reported recently. ${ }^{90}$

What's more, Nazar's group found that by coating a layer of $\mathrm{VO}_{x}$ onto CMK-3-S composites, the electrochemical reduction of polysulphides on the cathode surface is inhibited. ${ }^{95}$ Manthiram's group tried to incorporate $\mathrm{VO}_{2}$ (B) into sulfur cathodes to improve the performances but finally found $\mathrm{VO}_{2}(\mathrm{~B})$ was incompatible with the glyme-based electrolytes that are usually used in Li-S cells. ${ }^{96}$

\section{D. $\mathrm{SnO}_{x}$}

$\mathrm{SnO}_{2}$, was found to be a better conductive material than most other oxides in porous shell morphologies, ${ }^{97}$ therefore $\mathrm{SnO}_{2}$ shells with micromesopores were synthesized to load the sulfur inside by Zhang. ${ }^{97}$ The coreshell $\mathrm{S} / \mathrm{SnO}_{2}$ composites with $66 \mathrm{wt} \% \mathrm{~S}$ content exhibited a high initial capacity of $1176 \mathrm{~mA} \mathrm{~h} / \mathrm{g}$ at 0.5 $\mathrm{C}$ and retained a capacity of $736.6 \mathrm{~mA} \mathrm{~h} / \mathrm{g}$ after 50 cycles. To further enhance the conductivity and thus enhance the performance, double-shell $\mathrm{SnO}_{2} @ \mathrm{C}$ hollow nanospheres were designed to encapsulate sulfur by Cao. $^{98}$ The $\mathrm{S} / \mathrm{SnO}_{2} @ \mathrm{C}$ composite illustrated a high reversible capacity of $616 \mathrm{~mA} \mathrm{~h} / \mathrm{g}$ at $3200 \mathrm{~mA} / \mathrm{g}$ after 100 cycles.

Recently, Lee's group firstly reported multi-walled carbon nanotubes (MWCNT) filled with ordered tinmonoxide $(\mathrm{SnO})$ nanoparticles as the sulfur host for high-rate lithium-sulphur batteries. $^{99}$ The resulting MWCNT-SnO/S composite cathodes even exhibited a high capacity of $257.7 \mathrm{~mA} \mathrm{~h} / \mathrm{g}$ at an extremely high current rate of $20 \mathrm{C}$. Such an excellent rate capability could be attributed to the dipole-dipole interaction between the $\mathrm{SnO}$ and polysulphides as well as the MWCNT-SnO host accommodating the volume expansion, protecting the sulfur from dissolution, and enhancing the electrical conductivity. ${ }^{99}$

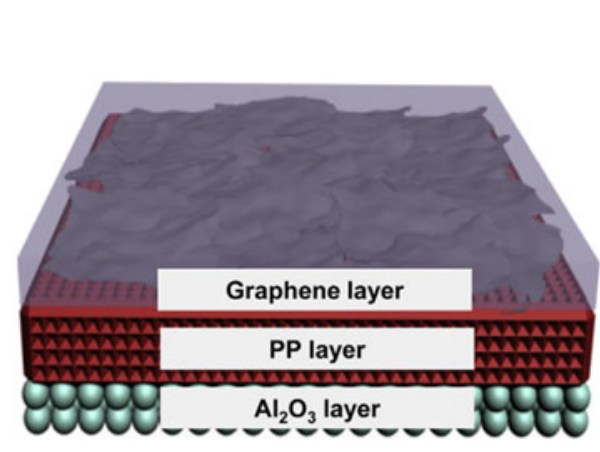

(a)

\section{E. $\mathrm{Al}_{2} \mathrm{O}_{3}$}

$\mathrm{Al}_{2} \mathrm{O}_{3}$ is an electrochemically inactive and ceramic material with a low cost and natural abundance. ${ }^{11}$ It was firstly applied as the additive in the sulfur cathode to improve the electrochemical performances of $\mathrm{Li}-\mathrm{S}$ batteries. ${ }^{100,101}$ Later $\mathrm{Al}_{2} \mathrm{O}_{3}$ was applied as the coating layer on both sulfur cathodes ${ }^{102-104}$ and separators, ${ }^{12,73,105}$ which has proved to be effective in enhancing the cycle stability of Li-S batteries. For instance, Shi's group coated an ultrathin $\mathrm{Al}_{2} \mathrm{O}_{3}$ film via ALD on the graphene-sulphur (G-S) composite. ${ }^{104}$ The ALD- $\mathrm{Al}_{2} \mathrm{O}_{3}$ coated-G-S composite cathode delivered a high specific capacity of $646 \mathrm{~mA} \mathrm{~h} / \mathrm{g}$ after 100 cycles at $0.5 \mathrm{C}$, which was about twice that of the bare G-S composite. Subsequently, Song et al., applied the $\mathrm{Al}_{2} \mathrm{O}_{3}$ and graphene to modify the polypropylene (GPA) separator for application in $\mathrm{Li}-\mathrm{S}$ batteries as shown in Fig. 3. ${ }^{106}$ The $\mathrm{Al}_{2} \mathrm{O}_{3}$ coating could further enhance the thermal stability and safety of the graphene coated polypropylene (GCP) separator.

Recently, porous $\mathrm{Al}_{2} \mathrm{O}_{3}$ was applied to protect the lithium anode by using a spin-coating method. ${ }^{11}$ The $\mathrm{Al}_{2} \mathrm{O}_{3}$ protective layer can restrict the side reactions between soluble lithium polysulphides and the lithium anode through a combination of physical separation and chemical adsorption by the $\mathrm{Al}_{2} \mathrm{O}_{3}$ layer, which can alleviate lithium corrosion due to polysulfide attack.

The ALD method is commonly used to deposit a very thin $\mathrm{Al}_{2} \mathrm{O}_{3}$ layer on the sulfur cathode or separator. The $\mathrm{Al}_{2} \mathrm{O}_{3}$ layer could not only enhance thermal stability of $\mathrm{Li}-\mathrm{S}$ batteries, but also can decrease the risk of short circuits. ${ }^{106}$ However, the mechanism of $\mathrm{Al}_{2} \mathrm{O}_{3}$-polysulfide chemical bonding still needs to be studied.

\section{F. $\mathrm{ZnO}$}

Zinc oxide $(\mathrm{ZnO})$ is a nontoxic n-type semiconductor with a wide band gap of $3.37 \mathrm{eV} .{ }^{107}$ Due to the large exciton binding energy of $60 \mathrm{meV}$ and the high

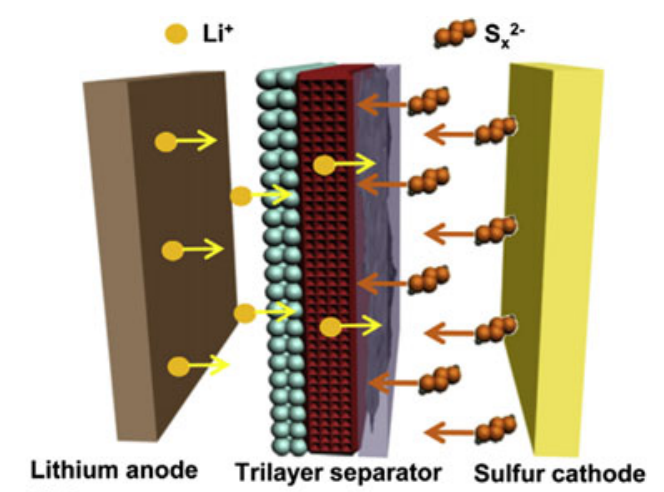

(b)

FIG. 3. Schematic illustration of (a) the structure of GPA separator, and (b) Li-S battery with GPA separator. Reproduced with permission from Ref. 106, Copyright 2016, Elsevier. 
mechanical, and thermal stabilities, $\mathrm{ZnO}$ is attractive for high-efficiency short-wavelength optoelectronic nanodevices. ${ }^{107}$ However, recently, $\mathrm{ZnO}$ attracts much attention as adsorbent for migrating polysulphides due to strong chemical bonding. ${ }^{13,108-110}$ Our group used ball-milling method to coat $\mathrm{ZnO}$ on the CNT-S cathode to improve the performances. ${ }^{13}$ The results showed that $\mathrm{ZnO}$ coatedCNT-S cathode illustrated much better cycling stability than that of CNT-S composites. While Gaoquan Shi's group used ALD method to coat $\mathrm{ZnO}$ on reduced graphene oxide (RGO)-sulphur composite. ${ }^{108}$ With the $\mathrm{ZnO}$ coating, the RGO-S composites exhibited high discharge capacity, excellent cycling stability and good rate-performance.

Recently, inspired by the brush-like membrane of cells for nutrient adsorption, a similar structure of interlayer consisting of $\mathrm{ZnO}$ nanowires and conductive frameworks as shown in Fig. 4 has been designed for chemical adsorption of polysulphides by Kumar and his co-workers. ${ }^{108}$ The S/MWCNTs composite cathode with a $\mathrm{ZnO} / \mathrm{C}$ interlayer exhibited a reversible capacity of $776 \mathrm{~mA} \mathrm{~h} / \mathrm{g}$ after 200 cycles at $1 \mathrm{C}$ with only $0.05 \%$ average capacity loss per cycle.

\section{G. Other metal oxide}

Intrinsically polar metal oxides, which can interact with polar lithium polysulphides, have been widely used to modify the sulphur-based cathodes, such as representative $\mathrm{Mg}_{0.8} \mathrm{Cu}_{0.2} \mathrm{O},{ }^{92} \mathrm{Mg}_{0.6} \mathrm{Ni}_{0.4} \mathrm{O},{ }^{111-113} \mathrm{Li}_{4} \mathrm{Ti}_{5} \mathrm{O}_{12},{ }_{114}^{114}$ $\mathrm{BaTiO}_{3},{ }_{115} \mathrm{LiFePO}_{4},{ }^{116} \mathrm{NiFe}_{2} \mathrm{O}_{4},{ }^{117} \mathrm{Co}_{3} \mathrm{O}_{4},{ }^{118,119}$ $\mathrm{ZrO}_{2},{ }^{120,121} \mathrm{MoO}_{2}{ }^{122}{ }^{12} \mathrm{MoO}_{3},{ }^{123} \mathrm{Nb}_{2} \mathrm{O}_{5},{ }^{124} \mathrm{~W}_{18} \mathrm{O}_{49},{ }^{125}$ $\mathrm{MgO},{ }^{33,126} \mathrm{CeO}_{2},{ }^{33,127} \mathrm{Fe}_{2} \mathrm{O}_{3},{ }^{128} \mathrm{La}_{2} \mathrm{O} 3,{ }^{33,129} \mathrm{CaO},{ }^{33}$ $\mathrm{In}_{2} \mathrm{O}_{3},{ }^{130}$ etc. Most of them are coupled with conductive polymers or carbon materials to overcome the inferior conductivity of both themselves and sulfur. For example, Zhou et al., ${ }^{121}$ incorporated a fine amount of $\mathrm{ZrO}_{2}$ to the holey CNT-sulphur composites. The holey CNT contributed to the good conductivity of the h-CNT/S/ZrO cathode, while appropriate $\mathrm{ZrO}_{2}$ loading preserved the permselective channels for $\mathrm{Li}^{+}$intercalation/deintercalation and trapped the soluble polysulphides.

These various metal oxides used in $\mathrm{Li}-\mathrm{S}$ batteries provide a new strategy for anchoring polysulphides. However, which group of metal oxides as well as the appropriate size and morphologies of the metal oxides that are most beneficial to trap the polysulfides should be further investigated. Further research is also needed to find whether the capture mechanism by various metal oxides is achieved via either monolayered or multilayered chemisorption.

\section{NANOSTRUCTURED METAL HYDROXIDES APPLICATION IN LI-S BATTERIES}

Metal hydroxides, filled with copious functional polar/ hydrophilic groups (e.g., hydrophilic groups, surface hydroxyl groups, and so on), ${ }^{131}$ are another promising class of encapsulation materials to build better $\mathrm{Li}-\mathrm{S}$ cells.

More recently, thin layered metal hydroxides, including $\mathrm{Co}(\mathrm{OH})_{2},{ }^{132} \mathrm{Co}(\mathrm{OH})_{2}$ /layered double hydroxides, ${ }^{133}$ $\mathrm{Ni}(\mathrm{OH})_{2},{ }^{13,134}$ and $\mathrm{Ni}_{3}\left(\mathrm{NO}_{3}\right)_{2}(\mathrm{OH})_{4}{ }^{131}$ have been used as effective encapsulation materials for sulfur cathodes. In one case, Lou's group designed double-shelled nanocages with two shells of cobalt hydroxide and layered double hydroxides (CH@LDH) as a conceptually new sulfur host, as shown in Fig. 5(a). ${ }^{133}$ Such a hollow CH@LDH polyhedra with complex shell structures not only maximize the advantages of hollow nanostructures for encapsulating a high content of sulfur ( $75 \mathrm{wt} \%$ ), but also provide sufficient self-functionalized surfaces for chemical bonding with polysulphides to suppress their outward dissolution. As a result, the resulted CH@LDH/S electrode with relatively high sulfur loading of $3 \mathrm{mg} / \mathrm{cm}^{2}$ showed excellent cycling stability at both 0.1 and $0.5 \mathrm{C}$ over 100 cycles, much better than the reference $\mathrm{C} / \mathrm{S}$ cathode as shown in Fig. 5(b).

The transition-metal hydroxides as coatings for the sulphur-based cathodes could effectively trap the polysulphides, but the mechanisms in which the transition-

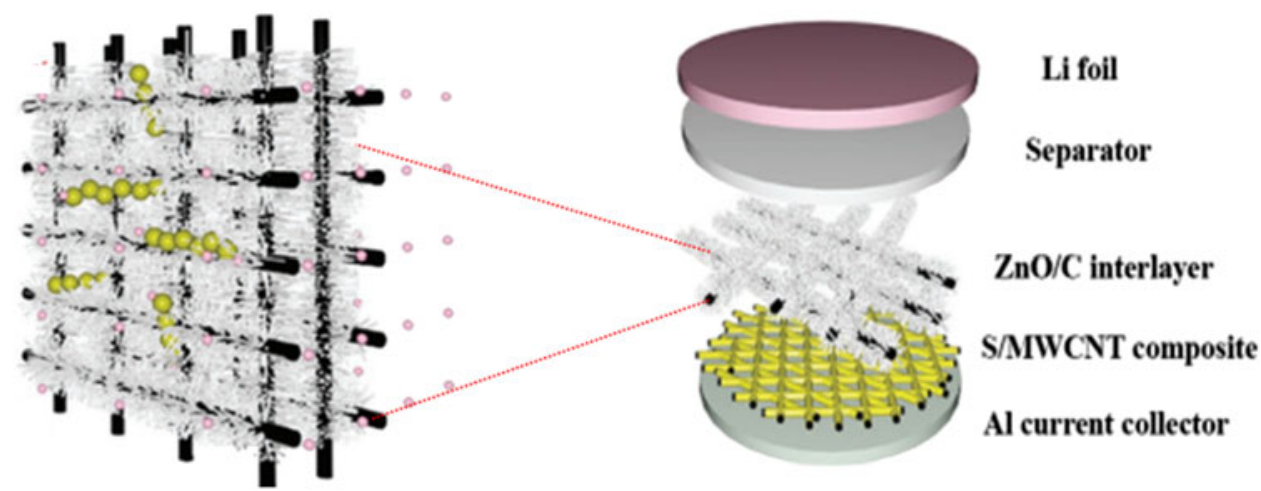

FIG. 4. Schematic of the structural and chemical function of the hybrid $\mathrm{ZnO}$ nanowires/carbon nanofibers interlayer in Li-S batteries. Reproduced with permission from Ref. 108, Copyright 2016, Wiley-VCH. 

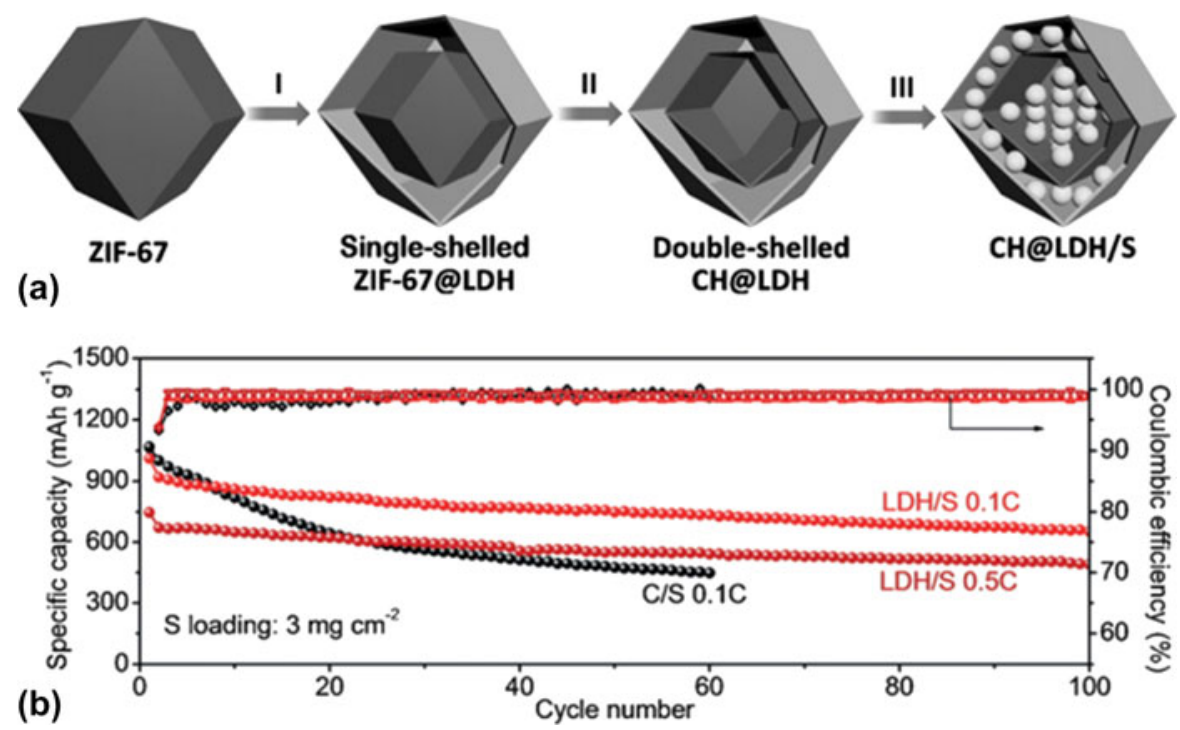

FIG. 5. (a) Schematic illustration of the synthesis of the CH@LDH/S composite. (b) Cycle performance comparison between CH@LDH/S and C/S. Reproduced with permission from Ref. 133, Copyright 2016, Wiley-VCH.

metal hydroxides bind with polysulphides should be further investigated to open a new avenue for future development of high performance $\mathrm{Li}-\mathrm{S}$ batteries.

\section{NANOSTRUCTURED METAL SULPHIDES APPLICATION IN LI-S BATTERIES}

\section{A. $\mathrm{TiS}_{2}$}

Titanium disulfide $\left(\mathrm{TiS}_{2}\right)$ is known as a cathode material in the first generation rechargeable lithium batteries. ${ }^{135}$ Due to its working voltage between 1.7 and $2.5 \mathrm{~V}$, very similar to the voltage range of Li-S cells, it has become a second active component in sulfur cathode. ${ }^{135}$ By adding the layered $\mathrm{TiS}_{2}$ into the carbon-S cathodes, the power capability of $\mathrm{Li}-\mathrm{S}$ cells has obviously improved. ${ }^{96,135}$

Recently, Archer's group developed a foam $\mathrm{TiS}_{2}$ and used it to encapsulate elemental sulfur. ${ }^{40}$ This $3 \mathrm{D}$ hybrid cathode demonstrated high areal specific capacity $\left(9 \mathrm{~mA} \mathrm{~h} / \mathrm{cm}^{2}\right)$ and high retention even at a relatively large areal mass loading of approximately $40 \mathrm{mg}$ sulfur per $\mathrm{cm}^{2}$ and high current density $\left(10 \mathrm{~mA} / \mathrm{cm}^{2}\right)$. Additionally, Cui's group used a two dimensional (2D) layered $\mathrm{TiS}_{2}$ to encapsulate $\mathrm{Li}_{2} \mathrm{~S} .{ }^{35}$ As a result, the core-shell $\mathrm{Li}_{2} \mathrm{~S} @ \mathrm{TiS}_{2}$ nanostructure was obtained. It also showed a very high area capacity of $3.0 \mathrm{~mA} \mathrm{~h} / \mathrm{cm}^{2}$ under high mass $\mathrm{Li}_{2} \mathrm{~S}$ loading (5.3 $\mathrm{mg} \mathrm{Li}_{2} \mathrm{~S}$ per $\mathrm{cm}^{2}$ ) and high-C rate conditions (4 C). That is because the $\mathrm{TiS}_{2}$ possesses a combination of high conductivity and polar Ti-S groups that can potentially interact strongly with $\mathrm{Li}_{2} \mathrm{~S}_{2} \mathrm{Li}_{2} \mathrm{~S}_{n}$ species. ${ }^{35,40} \mathrm{DFT}$ analysis and ab initio simulations demonstrated the binding energy between $\mathrm{Li}_{2} \mathrm{~S}$ and $\mathrm{TiS}_{2}$ was 10 times higher than that between $\mathrm{Li}_{2} \mathrm{~S}$ and carbon-based graphene.

\section{B. $\mathrm{Co}_{x} \mathrm{~S}_{y}$}

Cobalt sulphides commonly show unique metallic or half-metallic characteristics, which means they exhibit particularly high room temperature conductivity. ${ }^{41,42,136}$ Therefore the cobalt sulphides could afford efficient electron pathways and high electrocatalytic activity for polysulfide redox reactions in aqueous solutions. ${ }^{41}$ Simultaneously cobalt sulphides can significantly enhance the redox reactivity of lithium polysulphides due to their strong chemical affinity. ${ }^{41,42}$

For example, Zhang's group selected a cost-effective, nonporous mineral and bulk $\mathrm{CoS}_{2}$ as the additive to the carbon/sulfur composite cathodes. ${ }^{41}$ The adsorption experiment as shown in Fig. 6(a) and the First-principle calculations based on DFT as shown in Fig. 6(b) both proved the $\mathrm{CoS}_{2}$ showed far stronger affinities to the $\mathrm{Li}_{2} \mathrm{~S}_{4}$ compared to graphene. Meanwhile Nazar's group reported a metallic $\mathrm{Co}_{9} \mathrm{~S}_{8}$ with an interconnected graphene-like nano-architecture as the polysulphides host. ${ }^{42}$ The first-principles calculations coupled with spectroscopic evidence also demonstrated the synergistic strong dual-interactions of polysulphides with $\mathrm{Co}_{9} \mathrm{~S}_{8}$.

\section{C. $\mathrm{MoS}_{2}$}

$\mathrm{MoS}_{2}$, has a typical layered structure and the spacing between the neighboring layers for bulk $\mathrm{MoS}_{2}$ is about $0.615 \mathrm{~nm}$, which is significantly larger than that of graphite $(0.335 \mathrm{~nm}) .{ }^{137}$ It is a good candidate to encapsulate the sulfur. Furthermore, the $\mathrm{MoS}_{2}$ showed strong interaction with polysulphides, ${ }^{138-141}$ which makes it more attractive for use in $\mathrm{Li}-\mathrm{S}$ batteries.

Cui's group made a significant breakthrough on how $\mathrm{MoS}_{2}$ binds with $\mathrm{Li}_{2} \mathrm{~S}$. They used ab initio simulations to 


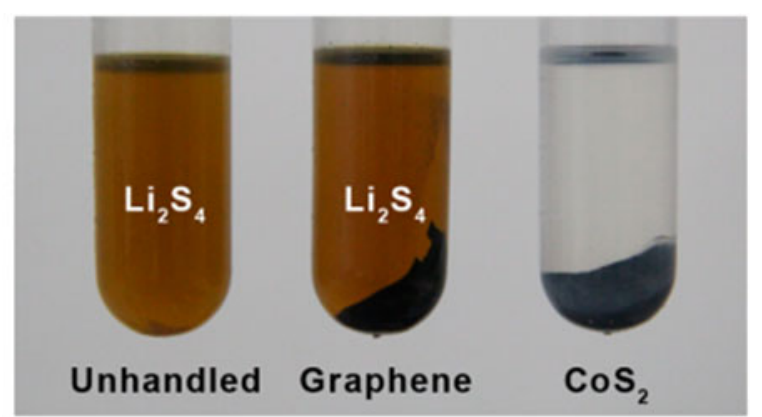

(a)

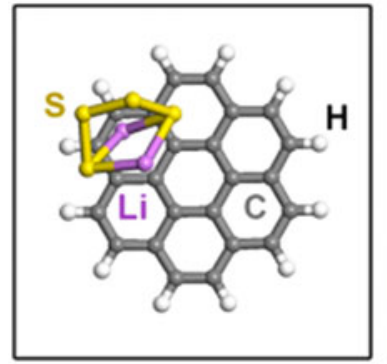

\section{$\mathrm{Li}_{2} \mathrm{~S}_{4}$-Graphene}

(b) $E_{b}=0.34 \mathrm{eV}$

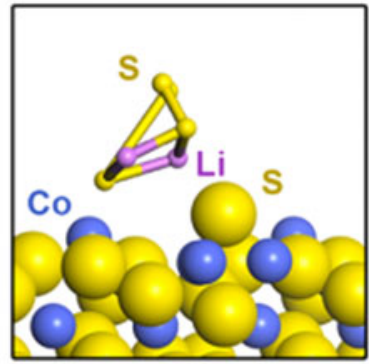

$\mathrm{Li}_{2} \mathrm{~S}_{4}-\mathrm{CoS}_{2}(111)$ $E_{b}=1.97 \mathrm{eV}$
FIG. 6. (a) Visualized adsorption of $\mathrm{Li}_{2} \mathrm{~S}_{4}$ on graphene and pristine $\mathrm{CoS}_{2}$ with the same surface area. (b) Binding geometries and energies of a $\mathrm{Li}_{2} \mathrm{~S}_{4}$ molecule on graphene (left, modeled as coronene) and (111) plane of $\mathrm{CoS}_{2}$ with cobalt-terminated surface (right), which is derived from theoretical calculation based on DFT. Reproduced with permission from Ref. 41, Copyright 2016, American Chemical Society.

choose the terrace and edge sites of $\mathrm{MoS}_{2}$ for binding $\mathrm{Li}_{2} \mathrm{~S} .{ }^{140}$ The calculation results showed that the binding energy between $\mathrm{Li}_{2} \mathrm{~S}$ with $\mathrm{MoS}_{2}$ terrace site was $\sim 0.87 \mathrm{eV}$, slightly higher than the case of graphene $(0.29 \mathrm{eV})$. While the edge sites, including Mo-edge and S-edge, binding energies were 4.48 and $2.70 \mathrm{eV}$, respectively, suggesting a large selectivity of edge versus terrace sites. In addition the $\mathrm{Li}_{2} \mathrm{~S}$ was superior to bind with Mo-edge sites. Such a new discovery becomes important in metal sulphides and metal oxides materials synthesis for $\mathrm{Li}-\mathrm{S}$ batteries.

\section{Other metal sulphides}

Apart from the metal sulphides illustrated above, various other metal sulphides, such as $\mathrm{SnS}_{2},{ }^{142,143} \mathrm{WS}_{2}{ }^{144}$ $\mathrm{MnS},{ }^{145} \mathrm{FeS}_{2},{ }^{146} \mathrm{FeS},{ }^{36} \mathrm{Ni}_{2} \mathrm{~S}_{3},{ }^{36} \mathrm{NiS}_{2},{ }^{147} \mathrm{VS}_{2},{ }^{35,36}$ $\mathrm{CuS},{ }^{148} \mathrm{Cu}_{3} \mathrm{BiS}_{3},{ }^{149} \mathrm{ZrS}_{2},{ }^{35}$ and so on, have also been investigated as polar hosts to reveal the key parameters correlated to the energy barriers and polysulfide adsorption capability in Li-S batteries. Even though most of the metal sulphides have better conductivity compared to the metal oxides, it still can't meet the demand for addressing internal resistance in the electrode, which is highly related to effective use of active materials. ${ }^{19}$ Thus various nanocarbon materials were combined with the metal sulphides to further improve the active materials utilization. For instance, $\mathrm{WS}_{2}$ nanosheets grown on the carbon nanofiber was used as the sulfur host. ${ }^{144}$ By combining the advantages of carbon nanofiber (excellent electronic transport of the 3D structure) and $\mathrm{WS}_{2}$ (polar adsorption of polysulphides), the resulted $\mathrm{C} @ \mathrm{WS}_{2} / \mathrm{S}$ composite still maintained with a high specific capacity of $502 \mathrm{~mA} \mathrm{~h} / \mathrm{g}$ at $2 \mathrm{C}$, about $90 \%$ of its initial specific capacity.

Although adding metal sulphides into S-carbon based cathodes has remarkably enhanced the electrochemical performance, there still exists a gap between practical applications. Additionally most of the adsorption mechanism for polysulphides on metal sulphides are still not clearly and need to be deeply investigated.

\section{NANOSTRUCTURED METAL CARBIDE APPLICATION IN LI-S BATTERIES}

Metal carbide are an exciting family of transition-metal carbides, ${ }^{37,150,151}$ which are inherently highly conductive and possess a highly active 2D surfaces to chemically bond to intermediate polysulphides by metal-sulphur interactions. ${ }^{37}$

Nazar's group first reported a new class of sulfur host materials-conductive MXene $\mathrm{Ti}_{2} \mathrm{C} .{ }^{37}$ The MXene $\mathrm{Ti}_{2} \mathrm{C}$, not only displays the characteristic high $2 \mathrm{D}$ electron conductivity of transition-metal carbides (much higher than GO), but also its exposed terminal metal sites can bind to the sulphides as revealed by X-ray photoelectron spectroscopy (XPS) analysis, with the corresponding mechanism scheme shown in Fig. $7 .^{37}$ Due to these superiorities, $\mathrm{Ti}_{2} \mathrm{C}$ was highly effective as a sulfur host material for $\mathrm{Li}-\mathrm{S}$ batteries, providing very stable cycling performance and high capacity even with $70 \mathrm{wt} \% \mathrm{~S}$.

From then on, the MXene $\mathrm{Ti}_{3} \mathrm{C}_{2},{ }^{152} \mathrm{Fe} 3 \mathrm{C},{ }^{150}$ and $\mathrm{TiC}^{153}$ as the sulfur host have been subsequently reported. All these transition-metal carbides demonstrated the strong interatomic attraction for the polysulphides.

\section{NANOSTRUCTURED METAL NITRIDE APPLICATION IN LI-S BATTERIES}

Metal nitrides couple the advantages of high electrical conductivity (batter than metal oxide and carbon) and the excellent chemical stability owing to the formation of an oxide passivation layer, ${ }^{38}$ which enable them to become potential host materials of sulfur.

Goodenough's group reported the use of mesoporous TiN to encapsulate sulfur by a melt-diffusion. ${ }^{38}$ The resulting mesoporous $\mathrm{TiN}-\mathrm{S}$ cathode delivered much better cycling stability and rate capability than both mesoporous $\mathrm{TiO}_{2}-\mathrm{S}$ and Vulcan $\mathrm{C}-\mathrm{S}$ cathode. The excellent overall electrochemical performance of a TiN-S cathode can be attributed to the good 


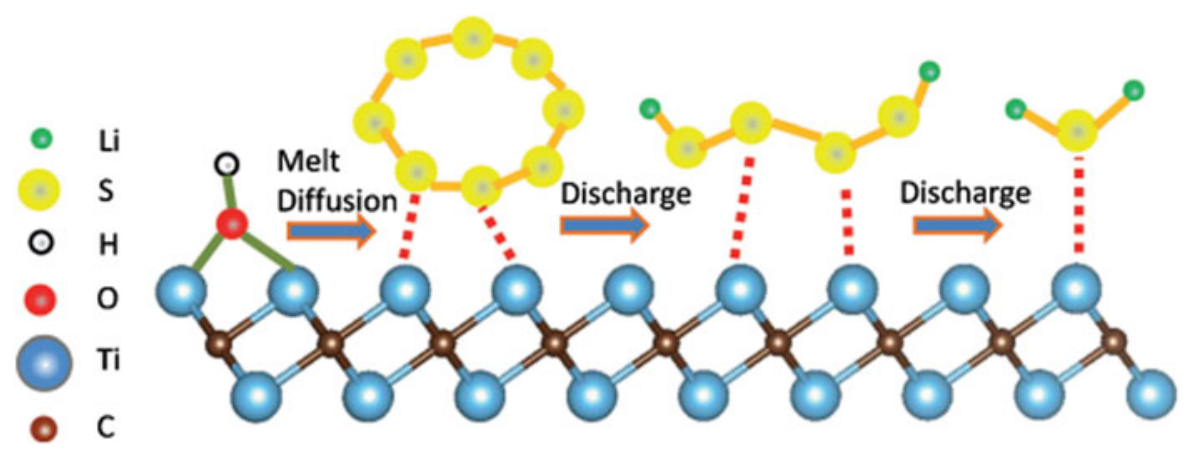

FIG. 7. Replacement of the Ti-OH bond on the MXene surface with a S-Ti-C bond on heat treatment or by contact with polysulfides. Reproduced with permission from Ref. 37, Copyright 2015, Wiley-VCH.

conductivity, robust framework of TiN, and the strong interactions between TiN and polysulphides. ${ }^{38}$ Not long ago, $\mathrm{Li}$ and his co-workers reported a 3D porous vanadium nitride/graphene (VN/G) composite as a chemical bridle for the polysulphides. ${ }^{154}$ The anchoring effect of vanadium nitride was confirmed by both experimental and theoretical results as shown in Fig. 8. It can be clearly observed that the absorption peak of $\mathrm{Li}_{2} \mathrm{~S}_{6}$ in the visible light remained in the solution with the addition of RGO but disappeared when adding the VN/G [Fig. 8(a)], indicating the strong adsorption of $\mathrm{Li}_{2} \mathrm{~S}_{6}$ molecules to polar VN. The First-principles calculations based on DFT demonstrated the binding energy between $\mathrm{Li}_{2} \mathrm{~S}_{6}$ and $\mathrm{VN}$ was $3.75 \mathrm{eV},{ }^{154}$ much higher than that on pyridinic $\mathrm{N}$-doped graphene. And the strong polar-polar interaction between $\mathrm{Li}_{2} \mathrm{~S}_{6}$ and $\mathrm{VN}$ resulted in an obvious deformation of the $\mathrm{Li}_{2} \mathrm{~S}_{6}$ molecule [Fig. 8(c)] compared to that of pyridinic N-doped graphene [Fig. 8(b)].

The pioneered works on TiN, $\mathrm{VN}$, and $\mathrm{Mo}_{2} \mathrm{~N}$ have shown the improved performances of $\mathrm{Li}-\mathrm{S}$ batteries by their high conductivity and strong chemical anchor functions, ${ }^{38,154,155}$ which opens a new direction of metal nitrides for energy storage.

\section{NANOSTRUCTURED MOFS APPLICATION IN LI-S BATTERIES}

MOFs are a class of porous materials assembled by connecting metal ions and organic linkers with tremendous extensiveness in variety and multiplicity. ${ }^{156}$ They usually have even richer pore structure and larger specific surface area than porous carbon. ${ }^{157}$ Thus, Tarascon pioneered the use of the MOF named MIL-100(Cr) as host material for sulfur impregnation. ${ }^{158}$ However, the confinement of polysulphides was mainly attributed to the bimodal pores of $\mathrm{MIL} 100(\mathrm{Cr})$ rather than weak binding by the oxygenated framework even though the cycling performances of sulfur cathode were improved. Since then, various groups have demonstrated that other MOFs can be adopted. ${ }^{39,156,157,159-161}$

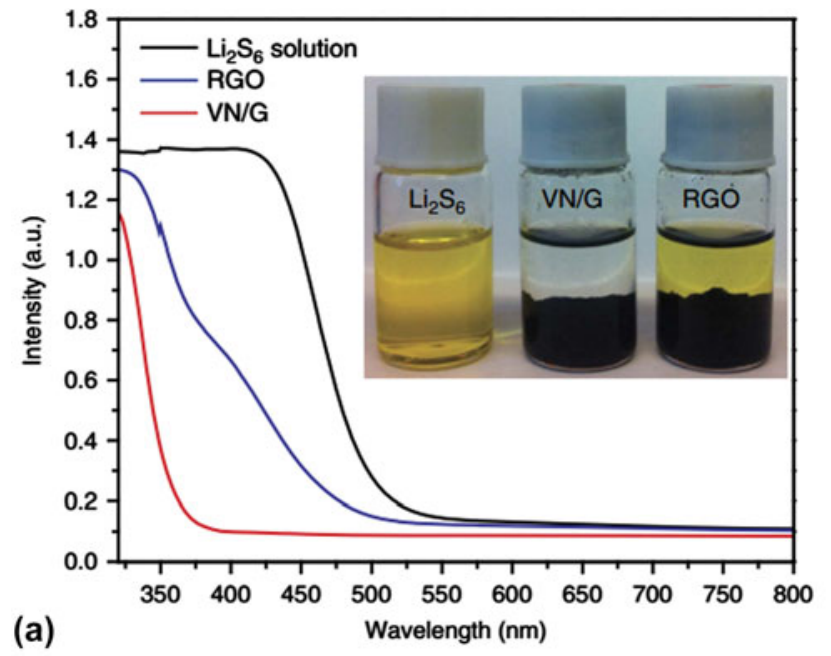

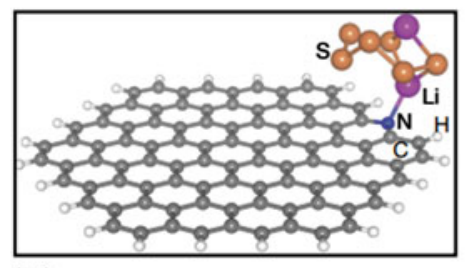

(b) $\mathrm{Li}_{2} \mathrm{~S}_{6}-\mathrm{N}$ doped graphene

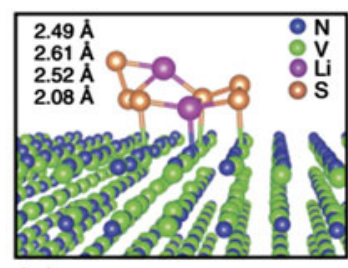

(c) $\mathrm{Li}_{2} \mathrm{~S}_{6}-\mathrm{VN}(200)$
FIG. 8. Demonstration of the strong interaction of VN/G composite with polysulphides. (a) Ultraviolet/visible absorption spectra of a $\mathrm{Li}_{2} \mathrm{~S}_{6}$ solution before and after the addition of RGO and VN/G. Inset image shows a photograph of a $\mathrm{Li}_{2} \mathrm{~S}_{6}$ solution before and an $2 \mathrm{~h}$ after the addition of graphene and VN/G. (b) Side view of a $\mathrm{Li}_{2} \mathrm{~S}_{6}$ molecule on a nitrogendoped graphene surface, the binding energy between $\mathrm{Li}_{2} \mathrm{~S}_{6}$ and pyridinic $\mathrm{N}$-doped graphene is calculated to be $1.07 \mathrm{eV}$. (c) Side view of $\mathrm{Li}_{2} \mathrm{~S}_{6}$ molecule on $\mathrm{VN}(200)$ surface, the binding energy between $\mathrm{Li}_{2} \mathrm{~S}_{6}$ and $\mathrm{VN}$ is calculated to be $3.75 \mathrm{eV}$. Reproduced with permission from Ref. 154, Copyright 2017, Nature Publishing Group.

Among which, Xiao's group proposed a mechanism of Lewis acid-base interactions between polysulphides and MOF. ${ }^{39}$ They used the Ni-MOF with interwoven mesopores $(\sim 2.8 \mathrm{~nm})$ and micropores $(\sim 1.4 \mathrm{~nm})$ as an ideal matrix to confine polysulphides. The Ni-MOF is constructed with coordinated $\mathrm{Ni}(\mathrm{II})$, which is a moderate/soft 
Lewis acid. The Lewis acidic Ni(II) center is inclined to coordinate with soluble polysulphides $\left(\mathrm{S}_{x}{ }^{2-}\right)$ anion (soft Lewis base) as axial ligand, which could effectively capture the soluble polysulphides within the cathode. To better understand the mechanism, the First-principles calculations based on DFT were performed by their group. The calculation results showed that only the S atom on one end point of polysulfide chain bound to the Ni-MOF with the corresponding interaction mechanism scheme shown in Fig. 9(a). Further binding energy calculation demonstrated the binding energies between Ni-MOF and polysulphides were higher than those between Co-MOF and polysulphides as shown in Fig. 9(b), which is consistent with the experiment results.

The fundamental understanding from Lewis acid-base interactions may provide new insights and opportunities to develop MOFs application in Li-S battery technology.

\section{SUMMARY AND PERSPECTIVE}

In summary, this comprehensive review has systematically demonstrated nearly all of the recent metal compounds from single-functional conductive additives to multifunctional key components in the Li-S battery. Although it is hard to foresee what the best metal compounds for Li-S batteries exactly will be, some key features can still be predicted based on current research and knowledge. First of all, the metal compounds should have strong interactions with polysulphides. According to the relative research by Nazar, ${ }^{162}$ the metal oxides with a moderate voltage (versus $\mathrm{Li} / \mathrm{Li}^{+}$), which form surfacebound thiosulfate via redox, are the most suitable for chemically binding polysulphides. $\mathrm{TiO}_{2}$, and $\mathrm{MnO}_{2}$ both display these characteristics. Secondly, when polysulphides are anchored on a conductive substrate, they receive electrons more easily which accelerates the kinetics of the polysulphide redox reactions. Thus, metal compounds with good conductivity, such as $\mathrm{CoS}_{2}$ $(6700 \mathrm{~S} / \mathrm{cm}),{ }^{41} \mathrm{TiC}\left(10^{4} \mathrm{~S} / \mathrm{cm}\right),{ }^{153}$ are better candidates for $\mathrm{Li}-\mathrm{S}$ batteries. However, most metal compounds should still be coupled with conductive polymers or carbon materials to enhance the overall conductivity of the cathode rather than relying on the intrinsic conductivity to attain the best service performances in the $\mathrm{Li}-\mathrm{S}$ batteries. Thirdly polar metal compounds, which can also serve as the electrocatalyst to facilitate the polysulphides redox reactions and increase the active materials utilization is preferable, of which $\mathrm{VN},{ }^{154} \mathrm{CoS}_{2},{ }^{41}$ and $\mathrm{MnO}_{2}{ }^{81}$ have been reported. Finally, the nanostructures of metal compounds, i.e., surface area, pore size, pore volume, as well as particle size are also important factors which influence the performance of Li-S batteries. ${ }^{19}$ Generally the metal compounds with smaller size ${ }^{69}$ high surface area and pore volume, ${ }^{98}$ and abundant micro/mesopores $^{49,57}$ are beneficial to the cathode.

Even though tremendous progress in improving the electrochemical performance and understanding the reaction mechanisms of Li-S batteries have been achieved, $\mathrm{Li}-\mathrm{S}$ batteries are far from being ready for practical use at this stage. Most of the reports on metal compoundssulphur-based cathodes displayed an areal sulfur loading of $0.3-1.5 \mathrm{mg} / \mathrm{cm}^{2},{ }^{19}$ which is far less than the requirement of $5.0 \mathrm{mg} / \mathrm{cm}^{2}$ for practical cells with high energy density of more than $300 \mathrm{~W} \mathrm{~h} / \mathrm{kg} .{ }^{19,163,164}$ Although some of the carbon-S cathode with an areal sulfur loading has exceeded $5 \mathrm{mg} / \mathrm{cm}^{2},{ }^{165-167}$ the cycling stability is not ideal. Therefore discovering how to balance the high tap density of metal compounds with the good conductivity of carbon in the nanostructured sulfur cathode is required to realise the practical applications. The 3D hybrid electrode with heteroatoms doped/functioned carbon and porous/hollow polar metal compounds is promising to fabricate $\mathrm{Li}-\mathrm{S}$ cells with high energy density and long cycle life. It is believed that $\mathrm{Li}-\mathrm{S}$ batteries could be a promising and practical technology for the applications in transportation and large-scale grid energy storage in the near future.
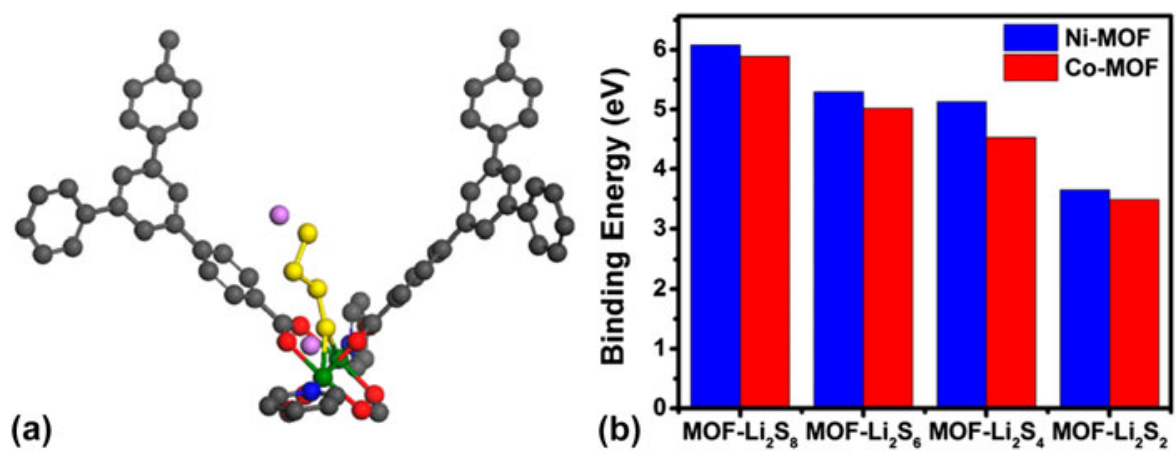

FIG. 9. (a) Schematic diagram illustrating the interaction between polysulfides (e.g., $\mathrm{Li}_{2} \mathrm{~S}_{8} / \mathrm{Li}_{2} \mathrm{~S}_{6} / \mathrm{Li}_{2} \mathrm{~S}_{4}$, and so forth) and paddle-wheel unit in NiMOF. C, O, N, S, Li, and $\mathrm{Ni}$ atoms are represented by gray, red, blue, yellow, pink, and green spheres, respectively. (b) Comparison of binding energies of lithium polysulfides to Ni-MOF or Co-MOF. Reproduced with permission from Ref. 39, Copyright 2016, American Chemical Society. 


\section{ACKNOWLEDGMENTS}

This work has been supported by the National Natural Science Foundation of China (Nos. 51572116 and 51202094); the Priority Academic Program Development of Jiangsu Higher Education Institutions.

\section{REFERENCES}

1. P.G. Bruce, S.A. Freunberger, L.J. Hardwick, and J.M. Tarascon: $\mathrm{Li}-\mathrm{O}_{2}$ and $\mathrm{Li}-\mathrm{S}$ batteries with high energy storage. Nat. Mater. 11(1), 19 (2012).

2. X.X. Gu, S.Q. Zhang, and Y.L. Hou: Graphene-based sulfur composites for energy storage and conversion in $\mathrm{Li}-\mathrm{S}$ batteries. Chin. J. Chem. 34(1), 11 (2016).

3. M.K. Song, E.J. Cairns, and Y. Zhang: Lithium/sulfur batteries with high specific energy: Old challenges and new opportunities. Nanoscale 5(6), 2186 (2013).

4. Y. Yang, G. Zheng, and Y. Cui: Nanostructured sulfur cathodes. Chem. Soc. Rev. 42(7), 3018 (2013).

5. L. Chen and L.L. Shaw: Recent advances in lithium-sulfur batteries. J. Power Sources 267, 770 (2014).

6. X. Gu, L. Hencz, and S. Zhang: Recent development of carbonaceous materials for lithium-sulphur batteries. Batteries 2(4), 33 (2016).

7. J. Liang, Z-H. Sun, F. Li, and H-M. Cheng: Carbon materials for Li-S batteries: Functional evolution and performance improvement. Energy Storage 2, 76 (2016).

8. X. Gu, Y. Wang, C. Lai, J. Qiu, S. Li, Y. Hou, W. Martens, N. Mahmood, and S. Zhang: Microporous bamboo biochar for lithium-sulfur batteries. Nano Res. 8(1), 129 (2015).

9. J. Liu, D.G.D. Galpaya, L. Yan, M. Sun, Z. Lin, C. Yan, C. Liang, and S. Zhang: Exploiting a robust biopolymer network binder for an ultrahigh-areal-capacity Li-S battery. Energy Environ. Sci. 10, 750-755 (2017).

10. L. Suo, Y.S. Hu, H. Li, M. Armand, and L. Chen: A new class of solvent-in-salt electrolyte for high-energy rechargeable metallic lithium batteries. Nat. Commun. 4, 1481 (2013).

11. H-K. Jing, L-L. Kong, S. Liu, G-R. Li, and X-P. Gao: Protected lithium anode with porous $\mathrm{Al}_{2} \mathrm{O}_{3}$ layer for lithium-sulfur battery. J. Mater. Chem. A 3(23), 12213 (2015).

12. G.C. Li, H.K. Jing, Z. Su, C. Lai, L. Chen, C.C. Yuan, H.H. Li, and L.L. Xiang: A hydrophilic separator for high performance lithium sulfur batteries. J. Mater. Chem. A 3, 11014 (2015).

13. X. Gu, C-J. Tong, B. Wen, L-M. Liu, C. Lai, and S. Zhang: Ballmilling synthesis of $\mathrm{ZnO} @$ sulphur/carbon nanotubes and $\mathrm{Ni}(\mathrm{OH})_{2} @$ sulphur/carbon nanotubes composites for highperformance lithium-sulphur batteries. Electrochim. Acta 196, 369 (2016).

14. J. Lee, T. Hwang, Y. Lee, J.K. Lee, and W. Choi: Coating of sulfur particles with manganese oxide nanowires as a cathode material in lithium-sulfur batteries. Mater. Lett. 158, 132 (2015).

15. X. Ji, K.T. Lee, and L.F. Nazar: A highly ordered nanostructured carbon-sulphur cathode for lithium-sulphur batteries. Nat. Mater. 8(6), 500 (2009).

16. X. Gu, C. Lai, F. Liu, W. Yang, Y. Hou, and S. Zhang: A conductive interwoven bamboo carbon fiber membrane for $\mathrm{Li}-\mathrm{S}$ batteries. J. Mater. Chem. A 3(18), 9502 (2015).

17. M-Q. Zhao, Q. Zhang, J-Q. Huang, G-L. Tian, J-Q. Nie, H-J. Peng, and F. Wei: Unstacked double-layer templated graphene for high-rate lithium-sulphur batteries. Nat. Commun. 5, 3410 (2014).

18. C. Zhang, H.B. Wu, C. Yuan, Z. Guo, and X.D. Lou: Confining sulfur in double-shelled hollow carbon spheres for lithium-sulfur batteries. Angew. Chem., Int. Ed. 124, 9730 (2012).
19. X. Liu, J.Q. Huang, Q. Zhang, and L. Mai: Nanostructured metal oxides and sulfides for lithium-sulfur batteries. Adv. Mater. 29, 1601759-1601784 (2017).

20. X. Gu, C.J. Tong, S. Rehman, L.M. Liu, Y. Hou, and S. Zhang: Multifunctional nitrogen-doped loofah sponge carbon blocking layer for high-performance rechargeable lithium batteries. ACS Appl. Mater. Interfaces 8(25), 15991 (2016).

21. L-B. Xing, K. Xi, Q. Li, Z. Su, C. Lai, X. Zhao, and R.V. Kumar: Nitrogen, sulfur-codoped graphene sponge as electroactive carbon interlayer for high-energy and -power lithium-sulfur batteries. J. Power Sources 303, 22 (2016).

22. X. Gu, C-J. Tong, C. Lai, J. Qiu, X. Huang, W. Yang, B. Wen, L-M. Liu, Y. Hou, and S. Zhang: Porous nitrogen and phosphorous dual doped graphene blocking layer for high performance Li-S batteries. J. Mater. Chem. A 3, 16670 (2015).

23. C.P. Yang, Y.X. Yin, H. Ye, K.C. Jiang, J. Zhang, and Y.G. Guo: Insight into the effect of boron doping on sulfur/ carbon cathode in lithium-sulfur batteries. ACS Appl. Mater. Interfaces 6(11), 8789 (2014).

24. Z. Wang, Y. Dong, H. Li, Z. Zhao, H.B. Wu, C. Hao, S. Liu, J. Qiu, and X.W. Lou: Enhancing lithium-sulphur battery performance by strongly binding the discharge products on amino-functionalized reduced graphene oxide. Nat. Commun. 5, 5002 (2014)

25. L. Wang, Z. Dong, D. Wang, F. Zhang, and J. Jin: Covalent bond glued sulfur nanosheet-based cathode integration for long-cyclelife Li-S batteries. Nano Lett. 13(12), 6244 (2013).

26. L. Zhou, X. Lin, T. Huang, and A. Yu: Binder-free phenyl sulfonated graphene/sulfur electrodes with excellent cyclability for lithium sulfur batteries. J. Mater. Chem. A 2(14), 5117 (2014).

27. A. Vizintin, M.U.M. Patel, B. Genorio, and R. Dominko: Effective separation of lithium anode and sulfur cathode in lithium-sulfur batteries. ChemElectroChem 1(6), 1040 (2014).

28. C. $\mathrm{Zu}$ and A. Manthiram: Hydroxylated graphene-sulfur nanocomposites for high-rate lithium-sulfur batteries. Adv. Energy Mater. 3, 1008 (2013).

29. L. Yin, J. Wang, F. Lin, J. Yang, and Y. Nuli: Polyacrylonitrile/ graphene composite as a precursor to a sulfur-based cathode material for high-rate rechargeable Li-S batteries. Energy Environ. Sci. 5(5), 6966 (2012).

30. W. Zhou, Y. Yu, H. Chen, F.J. DiSalvo, and H.D. Abruna: Yolk-shell structure of polyaniline-coated sulfur for lithiumsulfur batteries. J. Am. Chem. Soc. 135(44), 16736 (2013).

31. W. Li, Q. Zhang, G. Zheng, Z.W. Seh, H. Yao, and Y. Cui: Understanding the role of different conductive polymers in improving the nanostructured sulfur cathode performance. Nano Lett. 13(11), 5534 (2013).

32. G. Babu and L.M. Reddy Arava: Graphene-decorated graphitesulfur composite as a high-tap-density electrode for $\mathrm{Li}-\mathrm{S}$ batteries. RSC Adv. 5(59), 47621 (2015).

33. X. Tao, J. Wang, C. Liu, H. Wang, H. Yao, G. Zheng, Z.W. Seh, Q. Cai, W. Li, G. Zhou, C. Zu, and Y. Cui: Balancing surface adsorption and diffusion of lithium-polysulfides on nonconductive oxides for lithium-sulfur battery design. Nat. Commun. 7, 11203 (2016)

34. Z.W. Seh, W. Li, J.J. Cha, G. Zheng, Y. Yang, M.T. McDowell, P.C. Hsu, and Y. Cui: Sulphur- $\mathrm{TiO}_{2}$ yolk-shell nanoarchitecture with internal void space for long-cycle lithium-sulphur batteries. Nat. Commun. 4, 1331 (2013).

35. Z.W. Seh, J.H. Yu, W. Li, P.C. Hsu, H. Wang, Y. Sun, H. Yao, Q. Zhang, and Y. Cui: Two-dimensional layered transition metal disulphides for effective encapsulation of high-capacity lithium sulphide cathodes. Nat. Commun. 5, 5017 (2014). 
36. G. Zhou, H. Tian, Y. Jin, X. Tao, B. Liu, R. Zhang, Z.W. Seh, D. Zhuo, Y. Liu, J. Sun, J. Zhao, C. Zu, D.S. Wu, Q. Zhang, and Y. Cui: Catalytic oxidation of $\mathrm{Li}_{2} \mathrm{~S}$ on the surface of metal sulfides for Li-S batteries. Proc. Natl. Acad. Sci. U. S. A. 114 840-845 (2017).

37. X. Liang, A. Garsuch, and L.F. Nazar: Sulfur cathodes based on conductive MXene nanosheets for high-performance lithiumsulfur batteries. Angew. Chem., Int. Ed. 54(13), 3907 (2015).

38. Z. Cui, C. Zu, W. Zhou, A. Manthiram, and J.B. Goodenough: Mesoporous titanium nitride-enabled highly stable lithium-sulfur batteries. Adv. Mater. 28(32), 6926 (2016).

39. J. Zheng, J. Tian, D. Wu, M. Gu, W. Xu, C. Wang, F. Gao, M.H. Engelhard, J.G. Zhang, J. Liu, and J. Xiao: Lewis acidbase interactions between polysulfides and metal organic framework in lithium sulfur batteries. Nano Lett. 14(5), 2345 (2014).

40. L. Ma, S. Wei, H.L. Zhuang, K.E. Hendrickson, R.G. Hennig, and L.A. Archer: Hybrid cathode architectures for lithium batteries based on $\mathrm{TiS}_{2}$ and sulfur. J. Mater. Chem. A 3(39), 19857 (2015).

41. Z. Yuan, H.J. Peng, T.Z. Hou, J.Q. Huang, C.M. Chen, D.W. Wang, X.B. Cheng, F. Wei, and Q. Zhang: Powering lithium-sulfur battery performance by propelling polysulfide redox at sulfiphilic hosts. Nano Lett. 16(1), 519 (2016).

42. Q. Pang, D. Kundu, and L.F. Nazar: A graphene-like metallic cathode host for long-life and high-loading lithium-sulfur batteries. Mater. Horiz. 3(2), 130 (2016).

43. J. Zhang, Y. Shi, Y. Ding, W. Zhang, and G. Yu: In situ reactive synthesis of polypyrrole- $\mathrm{MnO}_{2}$ coaxial nanotubes as sulfur hosts for high-performance lithium-sulfur battery. Nano Lett. 16(11), 7276 (2016).

44. S. Evers, T. Yim, and L.F. Nazar: Understanding the nature of absorption/adsorption in nanoporous polysulfide sorbents for the Li-S battery. J. Phys. Chem. C 116(37), 19653 (2012).

45. R. Xu, J.C.M. Li, J. Lu, K. Amine, and I. Belharouak: Demonstration of highly efficient lithium-sulfur batteries. J. Mater. Chem. A 3(8), 4170 (2015).

46. Z.Z. Yang, H.Y. Wang, L. Lu, C. Wang, X.B. Zhong, J.G. Wang, and Q.C. Jiang: Hierarchical $\mathrm{TiO}_{2}$ spheres as highly efficient polysulfide host for lithium-sulfur batteries. Sci. Rep. 6, 22990 (2016)

47. Z. Liang, G. Zheng, W. Li, Z.W. Seh, H. Yao, K. Yan, D. Kong, and Y. Cui: Sulfur cathodes with hydrogen reduced titanium dioxide inverse opal structure. ACS Nano 8(5), 5249 (2014).

48. J. Li, J. Guo, J. Deng, and Y. Huang: Enhanced electrochemical performance of lithium-sulfur batteries by using mesoporous $\mathrm{TiO}_{2}$ spheres as host materials for sulfur impregnation. Mater. Lett. 189, 188 (2017).

49. C. Li, Z. Li, Q. Li, Z. Zhang, S. Dong, and L. Yin: MOFs derived hierarchically porous $\mathrm{TiO}_{2}$ as effective chemical and physical immobilizer for sulfur species as cathodes for high-performance lithium-sulfur batteries. Electrochim. Acta 215, 689 (2016).

50. K. Xie, Y. Han, W. Wei, H. Yu, C. Zhang, J-G. Wang, W. Lu, and B. Wei: Fabrication of a novel $\mathrm{TiO}_{2} / \mathrm{S}$ composite cathode for high performance lithium-sulfur batteries. RSC Adv. 5(94), 77348 (2015).

51. X.Z. Ma, B. Jin, H.Y. Wang, J.Z. Hou, X.B. Zhong, H.H. Wang, and P.M. Xin: S-TiO ${ }_{2}$ composite cathode materials for lithium/ sulfur batteries. J. Electroanal. Chem. 736, 127 (2015).

52. C.J. Hart, M. Cuisinier, X. Liang, D. Kundu, A. Garsuch, and L.F. Nazar: Rational design of sulphur host materials for $\mathrm{Li}-\mathrm{S}$ batteries: Correlating lithium polysulphide adsorptivity and selfdischarge capacity loss. Chem. Commun. 51(12), 2308 (2015).

53. Q. Li, Z. Zhang, K. Zhang, L. Xu, J. Fang, Y. Lai, and J. Li: Synthesis and electrochemical performance of $\mathrm{TiO}_{2}$-sulfur composite cathode materials for lithium-sulfur batteries. J. Solid State Electrochem. 17(11), 2959 (2013).
54. J. Li, B. Ding, G. Xu, L. Hou, X. Zhang, and C. Yuan: Enhanced cycling performance and electrochemical reversibility of a novel sulfur-impregnated mesoporous hollow $\mathrm{TiO}_{2}$ sphere cathode for advanced Li-S batteries. Nanoscale 5(13), 5743 (2013).

55. B. Ding, L. Shen, G. Xu, P. Nie, and X. Zhang: Encapsulating sulfur into mesoporous $\mathrm{TiO}_{2}$ host as a high performance cathode for lithium-sulfur battery. Electrochim. Acta 107, 78 (2013).

56. X. He, H. Hou, X. Yuan, L. Huang, J. Hu, B. Liu, J. Xu, J. Xie, J. Yang, S. Liang, and X. Wu: Electrocatalytic activity of lithium polysulfides adsorbed into porous $\mathrm{TiO}_{2}$ coated MWCNTs hybrid structure for lithium-sulfur batteries. Sci. Rep. 7, 40679 (2017).

57. T.A. Zegeye, C-F.J. Kuo, A.S. Wotango, C-J. Pan, H-M. Chen, A.M. Haregewoin, J-H. Cheng, W-N. Su, and B-J. Hwang: Hybrid nanostructured microporous carbon-mesoporous carbon doped titanium dioxide/sulfur composite positive electrode materials for rechargeable lithium-sulfur batteries. J. Power Sources 324, 239 (2016).

58. M. Yu, J. Ma, H. Song, A. Wang, F. Tian, Y. Wang, H. Qiu, and R. Wang: Atomic layer deposited $\mathrm{TiO}_{2}$ on a nitrogen-doped graphene/sulfur electrode for high performance lithium-sulfur batteries. Energy Environ. Sci. 9(4), 1495 (2016).

59. N. Moreno, Á. Caballero, J. Morales, and E. Rodríguez-Castellón: Improved performance of electrodes based on carbonized olive stones/S composites by impregnating with mesoporous $\mathrm{TiO}_{2}$ for advanced Li-S batteries. J. Power Sources 313, 21 (2016).

60. Y. Li, Q. Cai, L. Wang, Q. Li, X. Peng, B. Gao, K. Huo, and P.K. Chu: Mesoporous $\mathrm{TiO}_{2}$ nanocrystals/graphene as an efficient sulfur host material for high-performance lithium-sulfur batteries. ACS Appl. Mater. Interfaces 8(36), 23784 (2016).

61. J-Y. Hwang, H.M. Kim, S-K. Lee, J-H. Lee, A. Abouimrane, M.A. Khaleel, I. Belharouak, A. Manthiram, and Y-K. Sun: High-energy, high-rate, lithium-sulfur batteries: Synergetic effect of hollow $\mathrm{TiO}_{2}$-webbed carbon nanotubes and a dual functional carbon-paper interlayer. Adv. Energy Mater. 6(1), 1501480 (2016).

62. J.Q. Huang, Z. Wang, Z.L. Xu, W.G. Chong, X. Qin, X. Wang, and J.K. Kim: Three dimensional porous graphene aerogel cathode with high sulfur loading and embedded $\mathrm{TiO}_{2}$ nanoparticles for advanced lithium-sulfur batteries. ACS Appl. Mater. Interfaces 8, 28663 (2016).

63. L. Gao, M. Cao, Y.Q. Fu, Z. Zhong, Y. Shen, and M. Wang: Hierarchical $\mathrm{TiO}_{2}$ spheres assisted with graphene for a high performance lithium-sulfur battery. J. Mater. Chem. A 4(42), 16454 (2016).

64. H. Fan, Q. Tang, X. Chen, B. Fan, S. Chen, and A. Hu: Dualconfined sulfur nanoparticles encapsulated in hollow $\mathrm{TiO}_{2}$ spheres wrapped with graphene for lithium-sulfur batteries. Chem.-Asian J. 11(20), 2911 (2016).

65. Z. Zhang, Q. Li, K. Zhang, W. Chen, Y. Lai, and J. Li: Titaniumdioxide-grafted carbon paper with immobilized sulfur as a flexible free-standing cathode for superior lithium-sulfur batteries. $J$. Power Sources 290, 159 (2015).

66. Z. Zhang, Q. Li, S. Jiang, K. Zhang, Y. Lai, and J. Li: Sulfur encapsulated in $\mathrm{T} \mathrm{TiO}_{2}$-anchored hollow carbon nanofiber hybrid nanostructure for lithium-sulfur batteries. Chem.-Eur. J. 21(3), 1343 (2015).

67. Y. He, Z. Fu, Q. Zhou, M. Zhong, L. Yuan, J. Wei, X. Yang, C. Wang, and Y. Zeng: Fabrication and electrochemical behavior of a lithium-sulfur cell with a $\mathrm{TiO}_{2}$-sulfur-carbon aerogel-based cathode. Ionics 21(11), 3065 (2015).

68. H. Wang, S. Li, D. Li, Z. Chen, H.K. Liu, and Z. Guo: $\mathrm{TiO}_{2}$ coated three-dimensional hierarchically ordered porous sulfur electrode for the lithium/sulfur rechargeable batteries. Energy $\mathbf{7 5}$, 597 (2014). 
69. G. Liang, J. Wu, X. Qin, M. Liu, Q. Li, Y.B. He, J.K. Kim, B. Li, and F. Kang: Ultrafine $\mathrm{TiO}_{2}$ decorated carbon nanofibers as multifunctional interlayer for high-performance lithium-sulfur battery. ACS Appl. Mater. Interfaces 8(35), 23105 (2016).

70. C.Y. Fan, S.Y. Liu, H.H. Li, H.F. Wang, H.C. Wang, X.L. Wu, H.Z. Sun, and J. Zhang: Synergistic design of cathode region for the high-energy-density Li-S batteries. ACS Appl. Mater. Interfaces 8, 28689 (2016).

71. G. Xu, J. Yuan, X. Tao, B. Ding, H. Dou, X. Yan, Y. Xiao, and $X$. Zhang: Absorption mechanism of carbon-nanotube papertitanium dioxide as a multifunctional barrier material for lithiumsulfur batteries. Nano Res. 8, 3066 (2015).

72. Z. Xiao, Z. Yang, L. Wang, H. Nie, M. Zhong, Q. Lai, X. Xu, L. Zhang, and S. Huang: A lightweight $\mathrm{TiO}_{(2)} /$ graphene interlayer, applied as a highly effective polysulfide absorbent for fast, longlife lithium-sulfur batteries. Adv. Mater. 27(18), 2891 (2015).

73. H. Yao, K. Yan, W. Li, G. Zheng, D. Kong, Z.W. Seh, V.K. Narasimhan, Z. Liang, and Y. Cui: Improved lithiumsulfur batteries with a conductive coating on the separator to prevent the accumulation of inactive S-related species at the cathode-separator interface. Energy Environ. Sci. 7(10), 3381 (2014).

74. G. Zhou, Y. Zhao, C. Zu, and A. Manthiram: Free-standing $\mathrm{TiO}_{2}$ nanowire-embedded graphene hybrid membrane for advanced Li/dissolved polysulfide batteries. Nano Energy 12, 240 (2015).

75. F. Li, G. Wang, P. Wang, J. Yang, K. Zhang, Y. Liu, and Y. Lai: High-performance lithium-sulfur batteries with a carbonized bacterial cellulose $/ \mathrm{TiO}_{2}$ modified separator. J. Electroanal. Chem. 788, 150 (2017).

76. H. Wei, E.F. Rodriguez, A.S. Best, A.F. Hollenkamp, D. Chen, and R.A. Caruso: Chemical bonding and physical trapping of sulfur in mesoporous Magnéli $\mathrm{Ti}_{4} \mathrm{O}_{7}$ microspheres for highperformance Li-S battery. Adv. Energy Mater. 7(4), 1601616 (2017).

77. X. Tao, J. Wang, Z. Ying, Q. Cai, G. Zheng, Y. Gan, H. Huang, Y. Xia, C. Liang, W. Zhang, and Y. Cui: Strong sulfur binding with conducting Magnéli-phase $\mathrm{TinO}_{2 n-1}$ nanomaterials for improving lithium-sulfur batteries. Nano Lett. 14(9), 5288 (2014).

78. Q. Pang, D. Kundu, M. Cuisinier, and L.F. Nazar: Surfaceenhanced redox chemistry of polysulphides on a metallic and polar host for lithium-sulphur batteries. Nat. Commun. 5, 4759 (2014).

79. L. Ni, Z. Wu, G. Zhao, C. Sun, C. Zhou, X. Gong, and G. Diao: Core-shell structure and interaction mechanism of gamma- $\mathrm{MnO}_{2}$ coated sulfur for improved lithium-sulfur batteries. Small 13, 1603466-1603476 (2017).

80. X. Liang and L.F. Nazar: In situ reactive assembly of scalable core-shell sulfur- $\mathrm{MnO}_{2}$ composite cathodes. ACS Nano 10(4), 4192 (2016).

81. X. Liang, C. Hart, Q. Pang, A. Garsuch, T. Weiss, and L.F. Nazar: A highly efficient polysulfide mediator for lithiumsulfur batteries. Nat. Commun. 6, 5682 (2015).

82. H. Xu, L. Qie, and A. Manthiram: An integrally-designed, flexible polysulfide host for high-performance lithium-sulfur batteries with stabilized lithium-metal anode. Nano Energy 26, 224 (2016).

83. Y. Li, D. Ye, W. Liu, B. Shi, R. Guo, H. Zhao, H. Pei, J. Xu, and J. Xie: $\mathrm{A} \mathrm{MnO}_{2}$ /graphene oxide/multi-walled carbon nanotubessulfur composite with dual-efficient polysulfide adsorption for improving lithium-sulfur batteries. ACS Appl. Mater. Interfaces 8, 28566 (2016).

84. Z. Li, J. Zhang, and X.W. Lou: Hollow carbon nanofibers filled with $\mathrm{MnO}_{2}$ nanosheets as efficient sulfur hosts for lithium-sulfur batteries. Angew. Chem., Int. Ed. 54(44), 12886 (2015).
85. S. Rehman, T. Tang, Z. Ali, X. Huang, and Y. Hou: Integrated design of $\mathrm{MnO}_{2} @$ carbon hollow nanoboxes to synergistically encapsulate polysulfides for empowering lithium sulfur batteries. Small 13(20), 1700087 (2017).

86. W. Sun, X. Ou, X. Yue, Y. Yang, Z. Wang, D. Rooney, and K. Sun: A simply effective double-coating cathode with $\mathrm{MnO}_{2}$ nanosheets/graphene as functionalized interlayer for high performance lithium-sulfur batteries. Electrochim. Acta 207, 198 (2016).

87. Y. Guo, G. Zhao, N. Wu, Y. Zhang, M. Xiang, B. Wang, H. Liu, and $\mathrm{H}$. Wu: Efficient synthesis of graphene nanoscrolls for fabricating sulfur-loaded cathode and flexible hybrid interlayer toward high-performance $\mathrm{Li}-\mathrm{S}$ batteries. ACS Appl. Mater. Interfaces 8(50), 34185 (2016).

88. T. An, D. Deng, M. Lei, Q-H. Wu, Z. Tian, M. Zheng, and Q. Dong: $\mathrm{MnO}$ modified carbon nanotubes as a sulfur host with enhanced performance in Li/S batteries. J. Mater. Chem. A 4(33), 12858 (2016)

89. J. Liu, F. Liu, K. Gao, J. Wu, and D. Xue: Recent developments in the chemical synthesis of inorganic porous capsules. J. Am. Chem. Soc. 19(34), 6073 (2009).

90. M. Liu, Q. Li, X. Qin, G. Liang, W. Han, D. Zhou, Y.B. He, B. Li, and F. Kang: Suppressing self-discharge and shuttle effect of lithium-sulfur batteries with $\mathrm{V}_{2} \mathrm{O}_{5}$-decorated carbon nanofiber interlayer. Small 13(12), 1602539-1602545 (2017).

91. W. Li, J. Hicks-Garner, J. Wang, J. Liu, A.F. Gross, E. Sherman, J. Graetz, J.J. Vajo, and P. Liu: $\mathrm{V}_{2} \mathrm{O}_{5}$ polysulfide anion barrier for long-lived Li-S batteries. Chem. Mater. 26(11), 3403 (2014).

92. Y. Zhang, X. Wu, H. Feng, L. Wang, A. Zhang, T. Xia, and $\mathrm{H}$. Dong: Effect of nanosized $\mathrm{Mg}_{0.8} \mathrm{Cu}_{0.2} \mathrm{O}$ on electrochemical properties of $\mathrm{Li} / \mathrm{S}$ rechargeable batteries. Int. J. Hydrogen Energy 34(3), 1556 (2009).

93. Y. Zhang, L. Wang, A. Zhang, Y. Song, X. Li, H. Feng, X. Wu, and P. Du: Novel $\mathrm{V}_{2} \mathrm{O}_{5} / \mathrm{S}$ composite cathode material for the advanced secondary lithium batteries. Solid State Ionics 181(17-18), 835 (2010).

94. M-S. Kim, E.S. Shin, J-S. Kim, W.I. Cho, and S.H. Oh: The effect of $\mathrm{V}_{2} \mathrm{O}_{5} / \mathrm{C}$ additive on the suppression of polysulfide dissolution in Li-sulfur batteries. J. Electroceram. 33(3-4), 142 (2014).

95. K.T. Lee, R. Black, T. Yim, X. Ji, and L.F. Nazar: Surfaceinitiated growth of thin oxide coatings for Li-sulfur battery cathodes. Adv. Energy Mater. 2(12), 1490 (2012).

96. Y-S. Su and A. Manthiram: Sulfur/lithium-insertion compound composite cathodes for Li-S batteries. J. Power Sources 270, 101 (2014).

97. L.P. Zhang, Y.F. Wang, S.Q. Gou, and J.H. Zeng: All inorganic frameworks of Tin dioxide shell as cathode material for lithium sulfur batteries with improved cycle performance. J. Phys. Chem. C 119(52), 28721 (2015).

98. B. Cao, D. Li, B. Hou, Y. Mo, L. Yin, and Y. Chen: Synthesis of double-shell $\mathrm{SnO}_{2} @ \mathrm{C}$ hollow nanospheres as sulfur/sulfide cages for lithium-sulfur batteries. ACS Appl. Mater. Interfaces 8, 27795-27802 (2016)

99. A.Y. Kim, M.K. Kim, J.Y. Kim, Y. Wen, L. Gu, V-D. Dao, H-S. Choi, D. Byun, and J.K. Lee: Ordered SnO nanoparticles in MWCNT as a functional host material for high-rate lithiumsulfur battery cathode. Nano Res. 10, 2083 (2017)

100. Y.J. Choi, B.S. Jung, D.J. Lee, J.H. Jeong, K.W. Kim, H.J. Ahn, K.K. Cho, and H.B. Gu: Electrochemical properties of sulfur electrode containing nano $\mathrm{Al}_{2} \mathrm{O}_{3}$ for lithium/sulfur cell. Phys. Scr. T129, 62 (2007).

101. K. Dong, S. Wang, H. Zhang, and J. Wu: Preparation and electrochemical performance of sulfur-alumina cathode material for lithium-sulfur batteries. Mater. Res. Bull. 48(6), 2079 (2013). 
102. X. Han, Y. Xu, X. Chen, Y-C. Chen, N. Weadock, J. Wan, H. Zhu, Y. Liu, H. Li, G. Rubloff, C. Wang, and L. Hu: Reactivation of dissolved polysulfides in $\mathrm{Li}-\mathrm{S}$ batteries based on atomic layer deposition of $\mathrm{Al}_{2} \mathrm{O}_{3}$ in nanoporous carbon cloth. Nano Energy 2(6), 1197 (2013).

103. X. Li, J. Liu, B. Wang, M.N. Banis, B. Xiao, R. Li, T-K. Sham, and X. Sun: Nanoscale stabilization of Li-sulfur batteries by atomic layer deposited $\mathrm{Al}_{2} \mathrm{O}_{3}$. RSC Adv. 4(52), 27126 (2014).

104. M. Yu, W. Yuan, C. Li, J-D. Hong, and G. Shi: Performance enhancement of a graphene-sulfur composite as a lithium-sulfur battery electrode by coating with an ultrathin $\mathrm{Al}_{2} \mathrm{O}_{3}$ film via atomic layer deposition. J. Mater. Chem. A 2(20), 7360 (2014).

105. Z. Zhang, Y. Lai, Z. Zhang, K. Zhang, and J. Li: $\mathrm{Al}_{2} \mathrm{O}_{3}$-coated porous separator for enhanced electrochemical performance of lithium sulfur batteries. Electrochim. Acta 129, 55 (2014).

106. R. Song, R. Fang, L. Wen, Y. Shi, S. Wang, and F. Li: A trilayer separator with dual function for high performance lithium-sulfur batteries. J. Power Sources 301, 179 (2016).

107. F. Li, L. Yang, G. Xu, H. Xiaoqiang, X. Yang, X. Wei, Z. Ren, G. Shen, and G. Han: Hydrothermal self-assembly of hierarchical flower-like $\mathrm{ZnO}$ nanospheres with nanosheets and their application in Li-ion batteries. J. Alloys Compd. 577, 663 (2013).

108. T. Zhao, Y. Ye, X. Peng, G. Divitini, H-K. Kim, C-Y. Lao, P.R. Coxon, K. Xi, Y. Liu, C. Ducati, R. Chen, and R.V. Kumar: Advanced lithium-sulfur batteries enabled by a bio-inspired polysulfide adsorptive brush. Adv. Funct. Mater. 26(46), 8418 (2016).

109. M. Yu, A. Wang, F. Tian, H. Song, Y. Wang, C. Li, J.D. Hong, and G. Shi: Dual-protection of a graphene-sulfur composite by a compact graphene skin and an atomic layer deposited oxide coating for a lithium-sulfur battery. Nanoscale 7(12), 5292 (2015).

110. X. Liang, Q. Song, Y. Liu, and H. Liu: Preparation of $\mathrm{ZnO}$ porous nanostructures and its application in cathode material for lithium sulfur battery. Int. J. Electrochem. Sci. 10, 9333 (2015).

111. H. Tang, S. Yao, M. Jing, X. Wu, J. Hou, X. Qian, D. Rao, $\mathrm{X}$. Shen, X. Xi, and K. Xiao: $\mathrm{Mg}_{0.6} \mathrm{Ni}_{0.4} \mathrm{O}$ hollow nanofibers prepared by electrospinning as additive for improving electrochemical performance of lithium-sulfur batteries. J. Alloys Compd. 650, 351 (2015).

112. Y. Zhang, Y. Zhao, A. Yermukhambetova, Z. Bakenov, and P. Chen: Ternary sulfur/polyacrylonitrile $/ \mathrm{Mg}_{0.6} \mathrm{Ni}_{0.4} \mathrm{O}$ composite cathodes for high performance lithium/sulfur batteries. J. Mater. Chem. A 1(2), 295 (2013).

113. M-S. Song, S-C. Han, H-S. Kim, J-H. Kim, K-T. Kim, Y-M. Kang, H-J. Ahn, S.X. Dou, and J-Y. Lee: Effects of nanosized adsorbing material on electrochemical properties of sulfur cathodes for Li/S secondary batteries. J. Electrochem. Soc. 151(6), A791 (2004).

114. Y. Zhao, M. Liu, W. Lv, Y-B. He, C. Wang, Q. Yun, B. Li, F. Kang, and Q-H. Yang: Dense coating of $\mathrm{Li}_{4} \mathrm{Ti}_{5} \mathrm{O}_{12}$ and graphene mixture on the separator to produce long cycle life of lithium-sulfur battery. Nano Energy 30, 1 (2016).

115. K. Xie, Y. You, K. Yuan, W. Lu, K. Zhang, F. Xu, M. Ye, S. Ke, C. Shen, X. Zeng, X. Fan, and B. Wei: Ferroelectric-enhanced polysulfide trapping for lithium-sulfur battery improvement. Adv. Mater. 29(6), 1604724-1604729 (2017).

116. C.S. Kim, A. Guerfi, P. Hovington, J. Trottier, C. Gagnon, F. Barray, A. Vijh, M. Armand, and K. Zaghib: Facile dry synthesis of sulfur- $\mathrm{LiFePO}_{4}$ core-shell composite for the scalable fabrication of lithium/sulfur batteries. Electrochem. Commun. 32, 35 (2013).

117. Q. Fan, W. Liu, Z. Weng, Y. Sun, and H. Wang: Ternary hybrid material for high-performance lithium-sulfur battery. J. Am. Chem. Soc. 137(40), 12946 (2015).
118. H. Wang, T. Zhou, D. Li, H. Gao, G. Gao, A. Du, H. Liu, and Z. Guo: Ultrathin cobaltosic oxide nanosheets as an effective sulfur encapsulation matrix with strong affinity toward polysulfides. ACS Appl. Mater. Interfaces 9(5), 4320 (2017).

119. H. Cheng, S. Wang, D. Tao, and M. Wang: Sulfur $/ \mathrm{Co}_{3} \mathrm{O}_{4}$ nanotube composite with high performances as cathode materials for lithium sulfur batteries. Funct. Mater. Lett. 07(03), 1450020 (2014).

120. C. Wan, W. Wu, C. Wu, J. Xu, and L. Guan: A layered porous $\mathrm{ZrO}_{2} / \mathrm{RGO}$ composite as sulfur host for lithium-sulfur batteries. RSC Adv. 5(7), 5102 (2015).

121. Y. Zhou, C. Zhou, Q. Li, C. Yan, B. Han, K. Xia, Q. Gao, and $\mathrm{J}$. Wu: Enabling prominent high-rate and cycle performances in one lithium-sulfur battery: Designing permselective gateways for $\mathrm{Li}^{+}$transportation in holey-CNT/S cathodes. Adv. Mater. 27(25), 3774 (2015).

122. Q. Qu, T. Gao, H. Zheng, Y. Wang, X. Li, X. Li, J. Chen, Y. Han, J. Shao, and H. Zheng: Strong surface-bound sulfur in conductive $\mathrm{MoO}_{2}$ matrix for enhancing $\mathrm{Li}-\mathrm{S}$ battery performance. Adv. Mater. Interfaces 2(7), 1500048 (2015).

123. Z. Ma, Q. Liu, and S. Wang: Sulfur-graphene composite with molybdenum particles for stabilizing lithium-sulfur batteries. RSC Adv. 5(3), 2096 (2015).

124. Y. Tao, Y. Wei, J. Wang, Y. Liu, W. Qiao, L. Ling, and D. Long: Kinetically-enhanced polysulfide redox reactions by $\mathrm{Nb}_{2} \mathrm{O}_{5}$ nanocrystal for high-rate lithium-sulfur battery. Energy Environ. Sci. 9, 3230 (2016).

125. W. Zhang, C. Lin, S. Cong, J. Hou, B. Liu, F. Geng, J. Jin, $\mathrm{M}$. $\mathrm{Wu}$, and $\mathrm{Z}$. Zhao: $\mathrm{W}_{18} \mathrm{O}_{49}$ nanowire composites as novel barrier layers for $\mathrm{Li}-\mathrm{S}$ batteries based on high loading of commercial micro-sized sulfur. RSC Adv. 6(18), 15234 (2016).

126. R. Ponraj, A.G. Kannan, J.H. Ahn, and D.W. Kim: Improvement of cycling performance of lithium-sulfur batteries by using magnesium oxide as a functional additive for trapping lithium polysulfide. ACS Appl. Mater. Interfaces 8(6), 4000 (2016).

127. G-Q. Ma, Z-Y. Wen, Q-S. Wang, J. Jin, X-W. Wu, and J-C. Zhang: Effects of $\mathrm{CeO}_{2}$ nano-crystal on electrochemical properties of lithium/sulfur batteries. J. Inorg. Mater. 30(9), 913 (2015).

128. C. Zhao, C. Shen, F. Xin, Z. Sun, and W. Han: Prussian bluederived $\mathrm{Fe}_{2} \mathrm{O}_{3}$ /sulfur composite cathode for lithium-sulfur batteries. Mater. Lett. 137, 52 (2014).

129. F. Sun, J. Wang, D. Long, W. Qiao, L. Ling, C. Lv, and R. Cai: A high-rate lithium-sulfur battery assisted by nitrogen-enriched mesoporous carbons decorated with ultrafine $\mathrm{La}_{2} \mathrm{O}_{3}$ nanoparticles. J. Mater. Chem. A 1(42), 13283 (2013).

130. H. Yao, G. Zheng, P.C. Hsu, D. Kong, J.J. Cha, W. Li, Z.W. Seh, M.T. McDowell, K. Yan, Z. Liang, V.K. Narasimhan, and Y. Cui: Improving lithium-sulphur batteries through spatial control of sulphur species deposition on a hybrid electrode surface. Nat. Commun. 5, 3943 (2014).

131. J. Jiang, J. Zhu, W. Ai, X. Wang, Y. Wang, C. Zou, W. Huang, and T. Yu: Encapsulation of sulfur with thin-layered nickel-based hydroxides for long-cyclic lithium-sulfur cells. Nat. Commun. 6, 8622 (2015).

132. X-Q. Niu, X-L. Wang, D-H. Wang, Y. Li, Y-J. Zhang, Y-D. Zhang, T. Yang, T. Yu, and J-P. Tu: Metal hydroxideA new stabilizer for the construction of sulfur/carbon composites as high-performance cathode materials for lithium-sulfur batteries. J. Mater. Chem. A 3(33), 17106 (2015).

133. J. Zhang, H. Hu, Z. Li, and X.W. Lou: Double-shelled nanocages with cobalt hydroxide inner shell and layered double hydroxides outer shell as high-efficiency polysulfide mediator for lithiumsulfur batteries. Angew. Chem., Int. Ed. 55(12), 3982 (2016). 
134. X-Q. Niu, X-L. Wang, D. Xie, D-H. Wang, Y-D. Zhang, Y. Li, T. Yu, and J-P. Tu: Nickel hydroxide-modified sulfur/carbon composite as a high-performance cathode material for lithium sulfur battery. ACS Appl. Mater. Interfaces 7(30), 16715 (2015).

135. A. Garsuch, S. Herzog, L. Montag, A. Krebs, and K. Leitner: Performance of blended $\mathrm{TiS}_{2} /$ sulfur/carbon cathodes in lithiumsulfur cells. ECS Electrochem. Lett. 1, A24 (2012).

136. Z. Ma, Z. Li, K. Hu, D. Liu, J. Huo, and S. Wang: The enhancement of polysulfide absorption in LiS batteries by hierarchically porous $\mathrm{CoS}_{2}$ /carbon paper interlayer. J. Power Sources 325, 71 (2016).

137. S. Zhang, X. Yu, H. Yu, Y. Chen, P. Gao, C. Li, and C. Zhu: Growth of ultrathin $\mathrm{MoS}_{2}$ nanosheets with expanded spacing of (002) plane on carbon nanotubes for high-performance sodium-ion battery anodes. ACS Appl. Mater. Interfaces 6(24), 21880 (2014).

138. X. Li, K. Zhao, L. Zhang, Z. Ding, and K. Hu: $\mathrm{MoS}_{2}$-decorated coaxial nanocable carbon aerogel composites as cathode materials for high performance lithium-sulfur batteries. J. Alloys Compd. 692, 40 (2017).

139. E.P. Kamphaus and P.B. Balbuena: Long-chain polysulfide retention at the cathode of $\mathrm{Li}-\mathrm{S}$ batteries. J. Phys. Chem. C 120(8), 4296 (2016)

140. H. Wang, Q. Zhang, H. Yao, Z. Liang, H.W. Lee, P.C. Hsu, G. Zheng, and Y. Cui: High electrochemical selectivity of edge versus terrace sites in two-dimensional layered $\mathrm{MoS}_{2}$ materials. Nano Lett. 14(12), 7138 (2014).

141. P.T. Dirlam, J. Park, A.G. Simmonds, K. Domanik, C.B. Arrington, J.L. Schaefer, V.P. Oleshko, T.S. Kleine, K. Char, R.S. Glass, C.L. Soles, C. Kim, N. Pinna, Y.E. Sung, and J. Pyun: Elemental sulfur and molybdenum disulfide composites for $\mathrm{Li}-\mathrm{S}$ batteries with long cycle life and high-rate capability. ACS Appl. Mater. Interfaces 8(21), 13437 (2016).

142. X. Li, Y. Lu, Z. Hou, W. Zhang, Y. Zhu, Y. Qian, J. Liang, and Y. Qian: $\mathrm{SnS}_{2}$-compared to $\mathrm{SnO}_{2}$-stabilized $\mathrm{S} / \mathrm{C}$ composites toward high-performance lithium sulfur batteries. ACS Appl. Mater. Interfaces 8(30), 19550 (2016).

143. X. Li, L. Chu, Y. Wang, and L. Pan: Anchoring function for polysulfide ions of ultrasmall $\mathrm{SnS}_{2}$ in hollow carbon nanospheres for high performance lithium-sulfur batteries. Mater. Sci. Eng., B 205, 46 (2016).

144. T.Y. Lei, W. Chen, J.W. Huang, C.Y. Yan, H.X. Sun, C. Wang, W.L. Zhang, Y.R. Li, and J. Xiong: Multi-functional layered $\mathrm{WS}_{2}$ nanosheets for enhancing the performance of lithium-sulfur batteries. Adv. Energy Mater. 7(4), 1601843 (2017).

145. J.D. Liu, X.S. Zheng, Z.F. Shi, and S.Q. Zhang: Sulfur/ mesoporous carbon composites combined with $\gamma$-MnS as cathode materials for lithium/sulfur batteries. Ionics 20(5), 659 (2013).

146. S.S. Zhang and D.T. Tran: Pyrite $\mathrm{FeS}_{2}$ as an efficient adsorbent of lithium polysulphide for improved lithium-sulphur batteries. J. Mater. Chem. A 4(12), 4371 (2016).

147. Y. Lu, X. Li, J. Liang, L. Hu, Y. Zhu, and Y. Qian: A simple melting-diffusing-reacting strategy to fabricate $\mathrm{S} / \mathrm{NiS}_{2}-\mathrm{C}$ for lithium-sulfur batteries. Nanoscale 8(40), 17616 (2016).

148. K. Sun, D. Su, Q. Zhang, D.C. Bock, A.C. Marschilok, K.J. Takeuchi, E.S. Takeuchi, and H. Gan: Interaction of $\mathrm{CuS}$ and sulfur in $\mathrm{Li}-\mathrm{S}$ battery system. J. Electrochem. Soc. 162, A2834 (2015).

149. X. Gao, Y. Wang, Z. Ma, W. Jiang, Y. Zou, and C. Lu: A ternary sulphonium composite $\mathrm{Cu}_{3} \mathrm{BiS}_{3} / \mathrm{S}$ as cathode materials for lithium-sulfur batteries. J. Mater. Sci. 51(11), 5139 (2016).

150. J-Q. Huang, B. Zhang, Z-L. Xu, S. Abouali, M. Akbari Garakani, J. Huang, and J-K. Kim: Novel interlayer made from $\mathrm{Fe}_{3} \mathrm{C} /$ carbon nanofiber webs for high performance lithium-sulfur batteries. J. Power Sources 285, 43 (2015).

151. E.S. Sim, G.S. Yi, M. Je, Y. Lee, and Y-C. Chung: Understanding the anchoring behavior of titanium carbide-based MXenes depending on the functional group in $\mathrm{Li}-\mathrm{S}$ batteries: A density functional theory study. J. Power Sources 342, 64 (2017).

152. X. Zhao, M. Liu, Y. Chen, B. Hou, N. Zhang, B. Chen, N. Yang, K. Chen, J. Li, and L. An: Fabrication of layered $\mathrm{Ti}_{3} \mathrm{C}_{2}$ with an accordion-like structure as a potential cathode material for high performance lithium-sulfur batteries. J. Mater. Chem. A 3(15), 7870 (2015).

153. H.J. Peng, G. Zhang, X. Chen, Z.W. Zhang, W.T. Xu, J.Q. Huang, and Q. Zhang: Enhanced electrochemical kinetics on conductive polar mediators for lithium-sulfur batteries. Angew. Chem., Int. Ed. 55(42), 12990 (2016).

154. Z. Sun, J. Zhang, L. Yin, G. Hu, R. Fang, H.M. Cheng, and F. Li: Conductive porous vanadium nitride/graphene composite as chemical anchor of polysulfides for lithium-sulfur batteries. Nat. Commun. 8, 14627 (2017).

155. N. Mosavati, S.O. Salley, and K.Y.S. Ng: Characterization and electrochemical activities of nanostructured transition metal nitrides as cathode materials for lithium sulfur batteries. J. Power Sources 340, 210 (2017).

156. J. Zhou, R. Li, X. Fan, Y. Chen, R. Han, W. Li, J. Zheng, B. Wang, and $\mathrm{X}$. Li: Rational design of a metal-organic framework host for sulfur storage in fast, long-cycle $\mathrm{Li}-\mathrm{S}$ batteries. Energy Environ. Sci. 7(8), 2715 (2014).

157. W. Bao, Z. Zhang, Y. Qu, C. Zhou, X. Wang, and J. Li: Confine sulfur in mesoporous metal-organic framework@reduced graphene oxide for lithium sulfur battery. J. Alloys Compd. 582, 334 (2014).

158. R. Demir-Cakan, M. Morcrette, F. Nouar, C. Davoisne, T. Devic, D. Gonbeau, R. Dominko, C. Serre, G. Ferey, and J.M. Tarascon: Cathode composites for $\mathrm{Li}-\mathrm{S}$ batteries via the use of oxygenated porous architectures. J. Am. Chem. Soc. 133(40), 16154 (2011).

159. Y. Hou, H. Mao, and L. Xu: MIL-100(V) and MIL-100(V)/rGO with various valence states of vanadium ions as sulfur cathode hosts for lithium-sulfur batteries. Nano Res. 10(1), 344 (2016).

160. L. Bai, D. Chao, P. Xing, L.J. Tou, Z. Chen, A. Jana, Z.X. Shen, and Y. Zhao: Refined sulfur nanoparticles immobilized in metalorganic polyhedron as stable cathodes for $\mathrm{Li}-\mathrm{S}$ battery. ACS Appl. Mater. Interfaces 8(23), 14328 (2016).

161. Z. Zhao, S. Wang, R. Liang, Z. Li, Z. Shi, and G. Chen: Graphene-wrapped chromium-MOF(MIL-101)/sulfur composite for performance improvement of high-rate rechargeable $\mathrm{Li}-\mathrm{S}$ batteries. J. Mater. Chem. A 2(33), 13509 (2014).

162. X. Liang, C.Y. Kwok, F. Lodi-Marzano, Q. Pang, M. Cuisinier, H. Huang, C.J. Hart, D. Houtarde, K. Kaup, H. Sommer, T. Brezesinski, J. Janek, and L.F. Nazar: Tuning transition metal oxide-sulfur interactions for long life lithium sulfur batteries: The "Goldilocks" principle. Adv. Energy Mater. 6(6), 1501636 (2016).

163. M. Hagen, D. Hanselmann, K. Ahlbrecht, R. Maça, D. Gerber, and J. Tübke: Lithium-sulfur cells: The gap between the state-ofthe-art and the requirements for high energy battery cells. $A d v$. Energy Mater. 5(16), 1401986 (2015).

164. D. Lv, J. Zheng, Q. Li, X. Xie, S. Ferrara, Z. Nie, L.B. Mehdi, N.D. Browning, J-G. Zhang, G.L. Graff, J. Liu, and J. Xiao: High energy density lithium-sulfur batteries: Challenges of thick sulfur cathodes. Adv. Energy Mater. 5(16), 1402290 (2015).

165. R. Fang, S. Zhao, P. Hou, M. Cheng, S. Wang, H.M. Cheng, C. Liu, and F. Li: 3D interconnected electrode materials with ultrahigh areal sulfur loading for Li-S batteries. Adv. Mater. 28(17), 3374 (2016).

166. L. Miao, W. Wang, K. Yuan, Y. Yang, and A. Wang: A lithiumsulfur cathode with high sulfur loading and high capacity per area: A binder-free carbon fiber cloth-sulfur material. Chem. Commun. 50(87), 13231 (2014).

167. R. Fang, S. Zhao, S. Pei, X. Qian, P.X. Hou, H.M. Cheng, C. Liu, and F. Li: Toward more reliable lithium-sulfur batteries: An all-graphene cathode structure. ACS Nano 10(9), 8676 (2016). 